\title{
2008/43
}

Would empowering women initiate the demographic transition in least-developed countries?

David de la Croix and Marie Vander Donckt 
CORE

Voie du Roman Pays 34

B-1348 Louvain-la-Neuve, Belgium.

Tel (32 10) 474304

Fax (32 10) 474301

E-mail: corestat-library@uclouvain.be http://www.uclouvain.be/en-44508.html 


\title{
CORE DISCUSSION PAPER
}

$2008 / 43$

\section{Would empowering women initiate the demographic transition in least-developed countries?}

\author{
David DE LA CROIX ${ }^{1}$ and Marie VANDER DONCKT ${ }^{2}$
}

July 2008

\begin{abstract}
We examine the pathways by which gender inequality affects fertility and hampers growth. We introduce several dimensions of gender inequality into a 2-sex OLG model with a nonunitary representation of household decision-making. We characterize a Malthusian corner regime which is characterized by strong gender inequality in education and high fertility. We find both in theory and in the data that reducing the social and institutional gender gap does not help to escape from this regime while reducing the wage gender gap lowers fertility only in countries which have already escaped from it. The key policies to ease out the countries in the Malthusian regime are to promote mother's longevity and to curb infant mortality. In the interior regime, parents consider the impact of their children education on the expected intra-household bargaining position in their future couple. Education could thus compensate against the institutional and social gender gap that still exists in developed countries.
\end{abstract}

Keywords: gender gap, fertility, education, household bargaining.

JEL Classification: J13, O11, O40

${ }^{1}$ CORE and IRES, Université catholique de Louvain, Belgium. E-mail: david.delacroix@uclouvain.be. This author is also member of ECORE, the newly created association between CORE and ECORE.

${ }^{2}$ IRES, Université catholique de Louvain, Belgium. E-mail: marie.vanderdonckt@uclouvain.be

Authors acknowledge the financial support of the Belgian French speaking community (Grant ARC 03/08-235 "New macroeconomic approaches to the development problem") and the Belgian Federal Government (Grant PAI P6/07 "Economic Policy and Finance in the Global Economy: Equilibrium Analysis and Social Evaluation"). We thank Jean-Marie Baland, Matteo Cervellati and Bertrand Wigniolle for useful comments on a previous draft.

This paper presents research results of the Belgian Program on Interuniversity Poles of Attraction initiated by the Belgian State, Prime Minister's Office, Science Policy Programming. The scientific responsibility is assumed by the authors. 



\section{Introduction}

The drop of fertility close to - or below - replacement level has accompanied all developed countries along the transition from economic stagnation to sustained growth. Many least developed countries have now started their demographic transition and fertility is sharply decreasing there too. Still a group of countries seems not to have started its demographic transition yet with the regions of Sub-Saharian Africa and South Asia preeminently represented in this group of countries. Alongside high fertility, these countries are also characterized by gender inequality in education with women enjoying lower levels of schooling than men. ${ }^{1}$

Apart from being valuable on its own, a range of socio-economic virtues are widely attached to gender equality which includes improved children's development (through better health and education), reduced poverty and the promotion of long-term economic growth. In attest to the positive link between the status of women in a country and its economic development, programs aiming at the promotion of gender equality have emerged. Two emblematic examples are the World Bank's "Gender Action Plan as smart economics" and the United Nations that explicitly settles the promotion of gender equality and women empowerment as its third Millennium Development Goal.

Discernibly is gender equality a multi-dimensional concept that encompasses many other aspects than the sole access to education. Any comprehensive measure of gender parity in a society should indeed bear on a range of indicators capturing such features as women's access to economic resources, women's access to health programs, women's legal rights and civil liberties and so forth. In adequacy of this mindset, the World Economic Forum has implemented the Global Gender Gap (GGG) index that provides a concise measure of gender equality for a list of 128 countries. This index sums up a large variety of gender-based inequality indicators along four main dimensions: "Economic participation and opportunity", "educational attainment", "political empowerment" and, "health and survival". ${ }^{2}$

The usefulness of embracing multiple dimensions when considering the issue of gender equality is best disclosed by comparing the four GGG subindex scores of specific countries; for example, scores of Iran and Mozambique are displayed in Table 1. ${ }^{3}$ Despite

\footnotetext{
${ }^{1}$ See United Nations Statistics Division's country data release on total fertility rates and education indicators for women and men accessible via http://unstats.un.org/unsd/databases.htm.

${ }^{2}$ See the Global Gender Gap Report (2007). An alternative to this index of gender disparity is the very rich "Gender, Institutions and Development Database" from the OECD.

${ }^{3}$ Subindex scores are comprised between 0 (inequality) and 1 (equality). The index is built from female-to-male ratios in order to capture the gender gaps independently of the absolute women's and
} 
being relatively more egalitarian in the educational attainment dimension, Iran performs lower scores than Mozambique in terms of women's political empowerment and women's economic participation and opportunity. In addition, reporting the number of birth per women positively serves to illustrate the above-mentioned negative relationship between fertility and an educational gender gap unfavorable to women. Observe that Iran, where gender parity is near to be reached in education only, has a number of birth per women of only 2.03. Contrastingly, Mozambique combines a educational attainment female-to-male ratio well below unity with a high number of birth per woman, but gives more political and economic power to women compared to Iran. This observation raises the question of the relative pertinence of the various gender equality concepts when considering the issue of the economic development process.

Table 1: The Global Gender Gap index 2007: Iran and Mozambique

\begin{tabular}{lcccc}
\hline \hline & $\begin{array}{c}\text { Educational } \\
\text { Attainment }\end{array}$ & $\begin{array}{c}\text { Political } \\
\text { Empowerment }\end{array}$ & $\begin{array}{c}\text { Economic } \\
\text { Opportunity }\end{array}$ & $\begin{array}{c}\text { Birth per } \\
\text { Woman* }\end{array}$ \\
\hline Iran & 0.96 & 0.03 & 0.40 & 2.07 \\
Mozambique & 0.75 & 0.23 & 0.80 & 5.30 \\
\hline \hline
\end{tabular}

Sources: The Global Gender Gap Report 2007, World Economic Forum. *World Development Indicators, the World Bank Group, 2005.

Broader evidence for the negative link between female's access to education and fertility is suggested from a cross country data analysis. Figure 1 depicts the gender gap scores for the educational attainment GGG subindex together with the total fertility rate for a list of 128 countries. The coefficient of correlation between the two variables is equal to $-0,76$ (significant at the 0.005 probability level).

In this paper, we want to formally clarify the role of various dimensions to gender inequality in fostering the transition toward faster growth. Acknowledging the enhancing effect of a reduced population growth in the shift from economic stagnation to sustained growth, we especially want to examine the pathways by which increases in gender equality may affect fertility. We do so by means of a household bargaining model in which we explicitly distinguish between the following gender-based gaps: the survival gap, the wage gap, the social and institutional gap and the educational gap. The latter is endogenous to our analysis while the former three gender-based concepts are exogenous.

men's attainment levels which would not be independent of the level of available resources. This make the inter-country comparison possible regardless of their general level of development. 


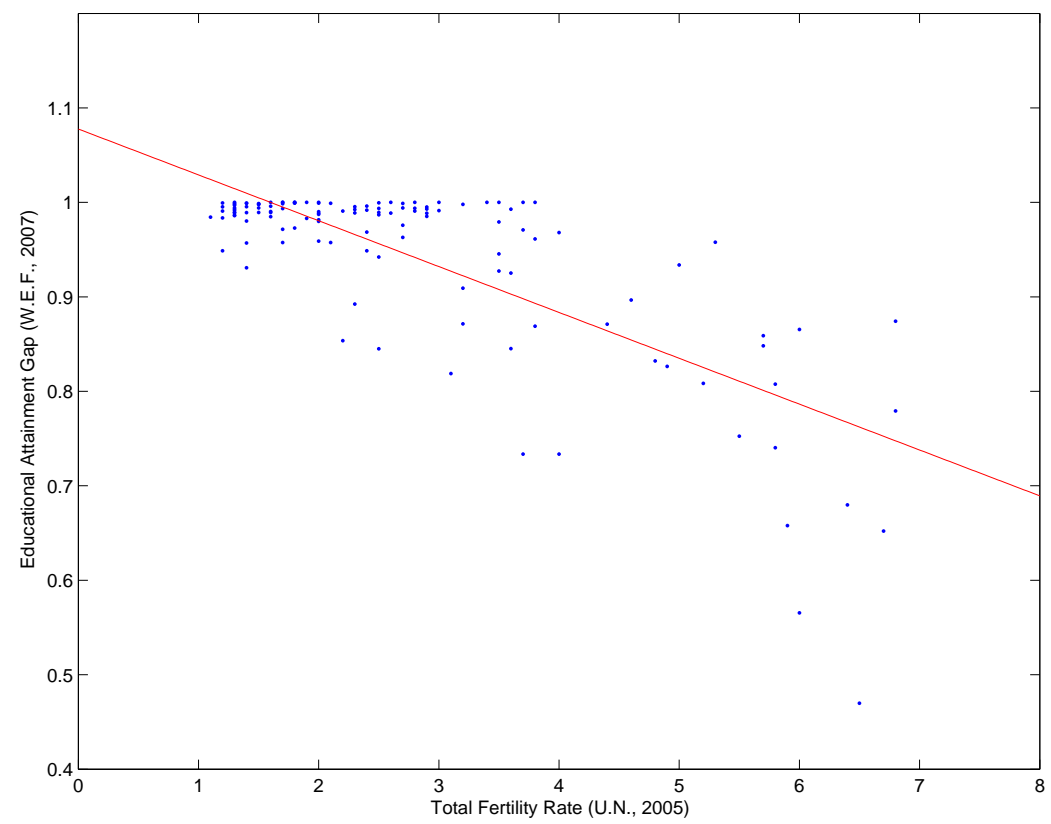

Figure 1: Female-to-Male Education and Fertility: Cross-Country Plot.

Specifically, we integrate a collective representation of household decision-making into a two-sex overlapping-generations model with endogenous fertility and parental investment in children's human capital. ${ }^{4}$ In this model, agents from both sexes are assumed to be perfectly identical except in their time constraint as women bear a higher time cost of childrearing. Fully abstracting from allegedly socially ascribed gender roles, this assumption is grounded on the inherent biological differences between genders that entail a higher time commitment to child care for women associated to pregnancy, childbirth and breastfeeding. ${ }^{5}$

In addition, parents care for the wellbeing of their children without favoring boys or girls a priori. A distinctive feature of the model comes with our specification of household

\footnotetext{
${ }^{4}$ Initiated by Chiappori $(1988,1992)$, collective models of household behavior emerged in response to the lack of both theoretical foundation and empirical support for the unitary - or "head of the household" - representation of family decision-making. See Chiappori and Donni (2006) for a survey of the literature on non-unitary models of household behaviors.

${ }^{5}$ Albanesi and Olivetti (2007) provide evidence for the time cost associated with breastfeeding. Combining information from the National Association of Pediatrics charts on the number of daily feedings by age of the infant with an estimated duration of 20 to 30 minutes for each feeding, the authors evaluate that a women spend on average 13.6 to 17.3 hours per week breast-feeding the infant. Based on this analysis, they conclude that on average, a women spend up to $43 \%$ of their working time nursing, given an average workweek of 40 hours during the first 12 months of life of the child.
} 
decision-making. It is based on the notion of intra-household bargaining power: pursuant to the collective household model, the welfare function of the couple is represented as a weighted sum of individual utilities where the weights can be interpreted as the bargaining power of the spouses in the decision process. We assume these weights to depend on the earning abilities of the spouses and, in particular, on the spouses's relative human capital levels. Altruistic parents make decisions on individual consumption levels, fertility, and the education of their children. Hence, parents face an inter-temporal arbitrage problem that involves decisions on consumption across generations with the double peculiarity of a quality-quantity tradeoff with respect to the offspring and a gender power variable that evolves over time. As in the standard model of parental investment in children's human capital, our model predicts that parents invest less, ceteris paribus, in the education of their daughters because of the lower amount of time devoted to labor market activities by women that reduces the returns to girls' education relative to that of boys. ${ }^{6}$ However, an additional consideration enters this investment decision as parents recognize that the equilibrium share their children, as adult, will extract from the household decision is linked to the human capital they have been endowed with and this may affect the direction of the gender gap in education.

In spite of the relatively abundant empirical literature on the impact of gender inequality for economic growth (see e.g. Knowles, Lorgelly and Owen, 2002), macroeconomic studies that formally explore the role of gender heterogeneity remain relatively sparse. ${ }^{7}$ Examples of dynamic models with endogenous fertility that explicitly embody non-unitary model of household behavior are Echevarria and Merlo (1999), and Iyigun and Walsh (2007). In both works, prior gender asymmetries are limited to biological disparities and gender differences in education is the equilibrium outcome of intra-household bargaining. However, since growth is left exogenous in both models, the authors don't use their model to investigate how these gender disparities may affect the long-run pattern of economic development. Echevarria and Merlo are interested in deriving a measure of the cost of having children that they estimate in a cross-country analysis. In Iyigun and Walsh, education is not chosen by parents but is seen as a pre-marital strategic investment decision that an agent make taking into account its implication in terms of future intra-household allocation of resources.

By relating the evolution of gender discrimination in education to long-run economic and demographic development in Europe, the work of Lagerlöf (2003a,2003b) borders

\footnotetext{
${ }^{6}$ See, for instance, Becker (1991) and Davies and Zhang (1995).

${ }^{7}$ Here, we want to refer in particular to dynamic model with gender discrimination that does not result from supposed asymmetries in terms of preferences or abilities.
} 
on our research program. The author develops a 2-sex dynamic model with endogenous fertility and household formation. Without assuming gender asymmetries in preferences and abilities, differences in parental investment in human capital between boys and girls may arise as a Nash equilibrium of a coordination game between families: when all other families discriminate, it is optimal for an atomistic parent to act the same. The author assumes that economies re-coordinate on more gender-equal equilibria over time without analyzing the driving forces toward higher gender equality. In addition, although integrating gender variables, the model builds on the unitary approach of the family. In that sense, the model does not response to the call for multi-person representations of the household. As the author notes, the model captures the concept of gender stereotypes but in regards with the above remark it does not capture the notion of gender decisional empowerment.

The present work also relates to the contribution of Doepke and Tertilt (2007) that explicitly addresses the issue of the change in women's status along the development process. Their work differs from existing literature in its angle of inquiry as the authors look at the other direction of causality in the relationship between women's empowerment and economic development. That is, they examine what economic force may have induce the progressive extension in women's rights during the industrialization process. They propose an OLG model with a quality-quantity trade-off on children and some political process to explain the distribution of power between men and women. Relying on the assumption of higher male physical strength, political power in this economy is initially concentrated in the hands of men. However, ongoing technological progress that augments the return to human capital may induce men to give in rights to women as this will allow for higher quality children and faster economic growth. We do not look at the political process through which advances in technology lead to women's empowerment. We rather direct the focus on the reversal causality direction, the specific question at hand here can be summarized in the following terms: What and how changes in gender disparities intervene in shaping the development process with a special emphasis on the demographic transition?

By introducing several dimensions of gender inequality into a 2-sex OLG model that encompasses a non-unitary representation of household decision-making, we are able to characterize a Malthusian corner regime in addition to the interior growth regime. The low growth Malthusian equilibrium is characterized by strong gender inequality in education and high fertility. The model displays this low-type equilibrium without need to assume non-convexities in the returns to human capital as it is generally the case in human capital-driven growth models built on the mode of Becker, Murphy and 
Tamura (1990). Indeed, while these authors required this assumption in order to produce the inferior equilibrium, the sole introduction in our set-up of gender heterogeneity in parental time requirements suffices to induce a motive for discrimination in the head of the parents and thereupon admitting a Malthusian equilibrium.

We also derive the model's implications in terms of the impact of the various dimension in gender disparity in shaping the economic development process. In particular, we show that reducing the social and institutional gender gap in economies trapped in the Malthusian regime does not help escaping it. Reducing the wage gender gap does not help either. The key policy measures which most likely will ease out these countries are to promote mother's health and longevity and to curb infant mortality. As we will argue when discussing the results, these facts are not inconsistent with empirical existing findings. In addition, we find both in theory and in the data that reducing the wage gender gap lowers fertility only in countries which have already escaped from the Malthusian regime.

The remainder of the paper is organized as follows. Section 1 sets out the model and outlines some broad implications of the bearing of the intra-household allocation process. Section 2 describes the Malthusian equilibrium with high fertility and gender disparities in education. It also discusses the condition on the different gender gaps to escape this low level equilibrium. The modern growth BGP is in turn presented in Section 3 and discusses the implication of the assumption of endogenous gender power. In section 4 , we confront the testable implications of the model to empirical evidence. Section 5 concludes.

\section{The Model}

We assume an overlapping-generations model in which individuals are either males or females and live for two periods: childhood and adulthood. Men and women are assumed to be perfectly identical except for the biologically founded difference of a longer child rearing time supplied by women. In the first period of life, children simply accumulate human capital and their consumption level is set equal to zero. At the beginning of adulthood, men and women are randomly matched into married couples. Adults are altruistic as they care for the well being of their children. Subject to the household resource constraint, married couples make decision on the spouses's consumption level, the number of children and the amount of education spending on daughters and sons. Preferences of the representative agent $i, i \in\{f, m\}$, in period $t$ are represented by the 
following utility function:

$$
V_{t}^{i}=u\left(c_{t}^{i}\right)+b\left(n_{t}\right) n_{t} \frac{\left(1-\theta_{t+1}\right) V_{t+1}^{f}+\theta_{t+1} V_{t+1}^{m}}{2}
$$

where $c_{t}^{i}$ is the consumption level, the function $b\left(n_{t}\right)$ characterizes the degree of altruism toward children following Barro and Becker (1988). $n_{t}$ is the number of children, half of whom are girls, and half are boys. That is, if single, individuals don't have children and only derive utility from consumption while, if married, individuals have preferences over consumption, the number of children, and the utility of their children. Notice that weights are attached to the welfare of daughters and sons via the variable $\theta_{t+1}$. This variable is an agglomerate that captures both "social norms" toward gender equality and some balance of power measure grounded on the distribution of human capital between men and women.

The time endowment of an adult individual is $p_{t}^{i}$. We allow this parameter to be gender specific in order to examine the impact of life expectancy differentials between men and women on the intra-household resource allocation and on economic dynamics. Men inelastically supply their time endowment to the labor market. Women are constrained in their amount of time to devote to the labor market as they are assumed to provide the whole time requirement associated with child rearing. With $\phi$ representing the fixed time cost per child, women are left with $p_{t}^{f}-\phi n_{t}$ units of time to supply to the labor market. Labor earnings of an individual $i$ depend on the current wage rate, $w_{t}^{i}$, and on her productivity as measured by her stock of human capital, $h_{t}^{i}$. The latter variable results from the parental decision on education expenditures. Thereof, men's and women's total labor incomes are, respectively, $p_{t}^{m} w_{t}^{m} h_{t}^{m}$ and $\left(p_{t}^{f}-\phi n_{t}\right) w_{t}^{f} h_{t}^{f}$.

In the following, we assume that all individuals enter marriage. In order to capture the multi-person dimension of the household, its welfare function is represented by a weighted sum of the individual utilities,

$$
V^{h}\left(h_{t}^{f}, h_{t}^{m}\right)=\theta_{t} V^{m}\left(h_{t}^{f}, h_{t}^{m}\right)+\left(1-\theta_{t}\right) V^{f}\left(h_{t}^{f}, h_{t}^{m}\right) .
$$

The welfare weight $\theta_{t}, \theta_{t} \in[0,1] \forall t$, can be interpreted as the bargaining power of the

\footnotetext{
${ }^{8}$ Allowing for gender-specific wage rates is consistent with the well documented persistence of a gender wage gap in competitive labor markets even when controlling for hours of work, labor market sectors or human capital characteristics. There exists a literature showing that unequal treatments in pay may arise as a coordination equilibrium between firms in competitive labor markets even under the assumption of women and men being perfectly identical ex ante, see Francois (1998) and Francois and Van Ours (2000).
} 
husband in the household decision process. Notice that in Equation (1), parents evaluate the welfare of their children through the lens of their expected bargaining positions in their future couple.

The welfare weight $\theta_{t}$ is assumed to be a function of the human capital stock of the spouses with the specific representation:

$$
\theta_{t}=(1-\gamma) \bar{\theta}+\gamma \frac{\left(h_{t}^{m}\right)^{\mu}}{\left(h_{t}^{m}\right)^{\mu}+\left(h_{t}^{f}\right)^{\mu}}
$$

with $\gamma, \gamma \in[0,1]$. This parameter measures the preponderance of human capital on the bargaining power distribution. ${ }^{9}$ When $\gamma$ equals zero, bargaining power is exogenous and equal to $\bar{\theta} \in[0,1]$. The ratio on the right-hand side of the above expression describes how human capital affects bargaining power with the parameter $\mu \geq 0$ describing the sensitivity of the function to relative human capital. The part of bargaining power associated to human capital of agent $i$ is equal to $1 / 2$ if $\mu=0$, while as $\mu \rightarrow \infty$, this dimension of bargaining power approaches unity for agent $i$ as soon as the human capital of $i$ surpasses that of $j, j \neq i$, even very slightly. ${ }^{10}$

Let $e_{t}^{f}$ and $e_{t}^{m}$ denote the amounts of education parents provide to daughters and sons at price $a$, total parental education expenditures on children are then equal to $a\left(e_{t}^{f}+e_{t}^{m}\right) \frac{n_{t}}{2}$. Assuming income pooling, and denoting income net of education spending by $y_{t}$, the budget constraint of the couple is given by

$$
c_{t}^{f}+c_{t}^{m}=\left(p_{t}^{f}-\phi n_{t}\right) w_{t}^{f} h_{t}^{f}+p_{t}^{m} w_{t}^{m} h_{t}^{m}-a\left(e_{t}^{f}+e_{t}^{m}\right) \frac{n_{t}}{2} \equiv y_{t} .
$$

In accordance with the presumption of men and women having identical abilities, we assume the same human capital technology for both gender groups:

$$
h_{t+1}^{i}=\left(e_{t}^{i}\right)^{\delta}\left(\bar{h}_{t}\right)^{1-\delta}
$$

with $\delta$, the human capital elasticity with respect to education, and $\bar{h}_{t}$, the average level of human capital in the parents's generation. It captures a positive intergenerational externality in the process of human capital accumulation. According to this production

\footnotetext{
${ }^{9}$ The specification of individual human capital as a determinant of intra-household decision power is consistent with recent empirical findings. Lührmann and Maurer (2007) find that education is associated with more individual decision power in the couple. In the same line, and Friedberg and Webb (2006) find that the effect of skill on bargaining power, measured by education and occupation, raises own and reduces spouse's relative decision power.

${ }^{10}$ Our representation of bargaining power shares with the contest success function the ratio functional representation (Skaperdas, 1996)
} 
function, a gender gap in human capital can solely arise from a parental bias in the education expenditure decision towards children of a specific gender group.

In what follows, we make additional assumptions on functional forms: we choose a CRRA specification with parameter $\sigma$ for the coefficient of relative risk aversion and, for the degree of parental altruism, we adopt the functional constant elasticity form $b\left(n_{t}\right)=\beta n_{t}^{-\epsilon}$ with $\beta \in[0,1]$ denoting the psychological discount factor, and $\epsilon \in[0,1]$ representing the elasticity of altruism with respect to the number of children. It is such that for given utility per pair of children $\left(V_{t+1}^{f}+V_{t+1}^{m}\right) / 2$, parental utility increases at a diminishing rate with the number of children $n_{t}$. In order to have a positive number of children we need the following parametric restriction (see Barro and Becker 1988 and 1989):

Assumption 1. $\sigma>\epsilon$.

This requires that the exponent of consumption $1-\sigma$ is smaller than the one associated to children, $1-\epsilon$, otherwise households always prefer consumption to having children.

In all period $t$, the couple solves the following optimization program:

$$
\begin{aligned}
V^{h}\left(h_{t}^{f}, h_{t}^{m}\right)=\max _{\left\{c_{t}^{f}, c_{t}^{m}, n_{t}, e_{t}^{f}, e_{t}^{m}\right\}}\left\{\left(1-\theta_{t}\right) \frac{\left(c_{t}^{f}\right)^{1-\sigma}}{1-\sigma}+\theta_{t} \frac{\left(c_{t}^{m}\right)^{1-\sigma}}{1-\sigma}\right. \\
\left.+\frac{1}{2} \beta n_{t}^{1-\epsilon}\left[\left(1-\theta_{t+1}\right) V^{f}\left(h_{t+1}^{f}, \tilde{h}_{t+1}^{m}\right)+\theta_{t+1} V^{m}\left(\tilde{h}_{t+1}^{f}, h_{t+1}^{m}\right)\right]\right\}
\end{aligned}
$$

subject to (3), (4) and (5), and to the following inequality constraints:

$$
n_{t} \leq \frac{p_{t}^{f}}{\phi}, e_{t}^{f} \geq 0, e_{t}^{m} \geq 0
$$

The tilde variables in the objective function, $\tilde{h}_{t+1}^{f}$ and $\tilde{h}_{t+1}^{m}$, represent the stock of human capital of the children's future wife and husband, respectively. These are taken as given as they result from the parental human capital investment choice of the children's future spouses. Hence, the decision on children's education by parents configures a strategic game played among families: When choosing the amount of education expenditures on children, parents need to solve the intra-household allocation problem their children will encounter as adults recognizing that both the total amount of resources to bargain over and the relative bargaining power of their own children will also be functions of the human capital of the children's spouses. Therefore, education on own children by a couple of parents is a best-response to the other parents's education decision on children. 
Anticipating on an after-specified result, note that in equilibrium all households behave in an identical manner so that perfect homogeneity within gender groups holds in every period and the issue of assortative mating does not come into the play.

Let us now look at the first order conditions of the household problem, which will allow us to identify some properties of the solution.

\section{Consumption}

The optimality condition with respect to spousal consumption is such that the consumption levels of the husband and the wife are proportional:

$$
\theta_{t}\left(c_{t}^{f}\right)^{\sigma}=\left(1-\theta_{t}\right)\left(c_{t}^{m}\right)^{\sigma}
$$

and, combined with the budget constraint, we obtain the individual consumption levels,

$$
\begin{aligned}
c_{t}^{m} & =\Theta_{t} y_{t}, \\
c_{t}^{f} & =\left(1-\Theta_{t}\right) y_{t},
\end{aligned}
$$

with $\Theta_{t}$ being a intra-household distribution variable following:

$$
\Theta_{t}=\frac{\theta_{t}^{1 / \sigma}}{\theta_{t}^{1 / \sigma}+\left(1-\theta_{t}\right)^{1 / \sigma}} .
$$

Beside the relative spousal bargaining powers, $\theta_{t}$ and $1-\theta_{t}$, the coefficient of risk aversion $\sigma$ also affects the final intra-household distribution of resources. When the coefficient of risk aversion is high, the final distribution is less sensitive to any imbalance between the individual bargaining powers. In the limit case when $\sigma$ becomes infinitely large we have

$$
\lim _{\sigma \rightarrow \infty} \Theta_{t}=\frac{1}{2}
$$

and the distribution of consumption between the spouses is perfectly equalized whatever the level of $\theta_{t}$. A conversely low coefficient of risk aversion renders the distribution of consumption very sensitive to an unbalanced distribution of spousal bargaining powers.

Our model implies complete compensation by the husband for the wife's labor income loss due to the presence of children in the household. Each spouse receives a fraction of the total household labor earnings and contributes for the very same fraction to the 
education expenditures. When $\gamma=0$ and $\theta_{t}=\bar{\theta}=1 / 2$, both spouses get exactly half of the household resources over and above education expenditures.

\section{Education}

Regarding optimal education levels, we obtain from the set of first order conditions

$$
\begin{aligned}
\frac{\theta_{t}}{\left(c_{t}^{m}\right)^{\sigma}} a n_{t}^{\epsilon} & \geq \beta \frac{\partial V^{m}\left(\tilde{h}_{t+1}^{f}, h_{t+1}^{m}\right)}{\partial e_{t}^{m}} \\
\frac{\theta_{t}}{\left(c_{t}^{m}\right)^{\sigma}} a n_{t}^{\epsilon} & \geq \beta \frac{\partial V^{f}\left(h_{t+1}^{f}, \tilde{h}_{t+1}^{m}\right)}{\partial e_{t}^{f}}
\end{aligned}
$$

where,

$$
\begin{aligned}
\frac{\partial V^{m}\left(\tilde{h}_{t+1}^{f}, h_{t+1}^{m}\right)}{\partial e_{t}^{m}} & =\frac{\partial \theta_{t+1}}{\partial e_{t}^{m}} \frac{\left(c_{t+1}^{m}\right)^{1-\sigma}}{1-\sigma}+\frac{\theta_{t+1}}{\left(c_{t+1}^{m}\right)^{\sigma}} p_{t+1}^{m} w_{t+1}^{m} \frac{\partial h_{t+1}^{m}}{\partial e_{t}^{m}} \\
\frac{\partial V^{f}\left(h_{t+1}^{f}, \tilde{h}_{t+1}^{m}\right)}{\partial e_{t}^{f}} & =\frac{\partial\left(1-\theta_{t+1}\right)}{\partial e_{t}^{f}} \frac{\left(c_{t+1}^{f}\right)^{1-\sigma}}{1-\sigma}+\frac{\theta_{t+1}}{\left(c_{t+1}^{m}\right)^{\sigma}}\left(p_{t+1}^{f}-\phi n_{t+1}\right) w_{t+1}^{f} \frac{\partial h_{t+1}^{f}}{\partial e_{t}^{f}}
\end{aligned}
$$

At an interior solution, the above optimality conditions hold as equalities. The lefthand side in (10)-(11) represents the cost of an additional unit of education while the right-hand side is the associated marginal benefit. As in the standard model of parental investment in children's human capital, the higher the marginal productivity or "earning ability" of the son (daughter), the higher the marginal utility for the parent from investing in their son's (daughter's) education. This is captured by the utter right terms of (12) and (13). The first term on the right-hand side instead captures the additional effect of the impact of the education decision on the next generation's distribution of bargaining power. Indeed, within this framework, parental decisions on investment in human capital of sons and daughters will tilt the intra-household allocation of their children's future couple.

Given the assumption of diminishing returns to education in the human capital accumulation function, a higher fertility further decreases the amount of education spending on girls relative to that on boys, all else being equal. In addition, parents increase the human capital of their daughter (son) in response to an increase in the husband's (wife's) stock of human capital. This results from the specification on the intra-household allocation process.

In the strategic game played by families of choosing own children's human capital given 
that of children in other families, parents simultaneously face a perfectly symmetric decision problem resulting in best response functions (10) and (11). At equilibrium, all parents choose the same level of education for their daughter and for their son so that $\tilde{h}_{t}^{f}=h_{t}^{f}$ and $\tilde{h}_{t}^{m}=h_{t}^{m}$ in a symmetric pure strategy Nash equilibrium. As a result, the value function (6) can be rewritten by dropping the tilde and using (2):

$$
V^{h}\left(h_{t}^{f}, h_{t}^{m}\right)=\max _{\left\{c_{t}^{f}, c_{t}^{m}, n_{t}, h_{t+1}^{f}, h_{t+1}^{m}\right\}}\left\{\left(1-\theta_{t}\right) \frac{\left(c_{t}^{f}\right)^{1-\sigma}}{1-\sigma}+\theta_{t} \frac{\left(c_{t}^{m}\right)^{1-\sigma}}{1-\sigma}+\frac{\beta n_{t}^{1-\epsilon}}{2} V^{h}\left(h_{t+1}^{f}, h_{t+1}^{m}\right)\right\} .
$$

\section{Fertility}

The first order condition with respect to the number of children is given by

$$
(1-\epsilon) \frac{\beta n_{t}^{-\epsilon}}{2} V^{h}\left(h_{t+1}^{f}, h_{t+1}^{m}\right) \geq \frac{\theta_{t}}{\left(c_{t}^{m}\right)^{\sigma}}\left[\frac{a}{2}\left(e_{t}^{f}+e_{t}^{m}\right)+\phi w_{t}^{f} h_{t}^{f}\right]
$$

with strict equality at an interior solution. The left-hand side represents the marginal gain for parents from an additional pair of children while the right-hand side corresponds to the effect on utility associated to children in terms of forgone individual consumption for given quality of the children. It includes both the direct education cost and the opportunity cost in terms of lost earnings for the mother.

Let us conclude the presentation of the model by highlighting the different concepts of gender inequality embedded in it. Three of them are exogenous: we define the survival gap by the ratio of total time endowments, $p^{m} / p^{f}$. Secondly, the wage gap is measured by $w^{m} / w^{f}$. The last exogenous indicator is our so-called social and institutional gap enclosed in the parameter $\bar{\theta}$. This concept captures the societal and institutional propensity of a country toward higher gender equality (think of it as a compound indicator enclosing a wide set of elements ranging from family norms and codes, physical integrity, civil liberties to women's open access to the political decision-making). Additionally, the following set of gaps is endogenous to our model: the educational gap, $e^{m} / e^{f}$, the participation gap, $p^{m} /\left(p^{f}-\phi n\right)$, and the distribution gap which we define to be the ratio of individual consumption levels, $c^{m} / c^{f}$. Note that by expression (8), it is also measurable by the ratio of the distribution factors, $\Theta /(1-\Theta)$. Interestingly, the above list of gender gap concepts can be re-framed in the four pillars structure of the Global Gender Gap Indicator. We indeed find elements falling into each of the four categories defined by the World Economic Forum: the ratios $w^{m} / w^{f}, p^{m} /\left(p^{f}-\phi n\right)$ would

pertain to the "economic participation and opportunity" category, the ratio $e^{m} / e^{f}$ to the 
"educational attainment" indicator, whereas the "health and survival" is captured by our $p^{m} / p^{f}$. Finally, $\bar{\theta}$ could be classified in "political empowerment". While characterizing the various possible regimes of our model economy, we will pay a special attention to the relationship between these different measures of gender inequalities.

\section{The Malthusian Corner Equilibrium}

Before defining balanced growth path solutions (BGP), let us characterize the dynamics of our economy in terms of stationary variables. The stationary variables are defined as: $1+g_{t}=\frac{\bar{h}_{t+1}}{h_{t}}, \hat{c}_{t}^{f}=c_{t}^{f} / \bar{h}_{t}, \hat{c}_{t}^{m}=c_{t}^{m} / \bar{h}_{t}, \hat{e}_{t}^{f}=e_{t}^{f} / \bar{h}_{t}, \hat{e}_{t}^{m}=e_{t}^{m} / \bar{h}_{t}, \hat{h}_{t}^{f}=h_{t}^{f} / \bar{h}_{t}, \hat{h}_{t}^{m}=h_{t}^{m} / \bar{h}_{t}$, $\hat{V}_{t}=V_{t} / \bar{h}_{t}^{1-\sigma}, \hat{y}_{t}=y_{t} / \bar{h}_{t}$.

Definition 1 Given initial conditions $\left(h_{0}^{f}, h_{0}^{m}\right)$, an equilibrium is a vector $\left\{\theta_{t}, \hat{y}_{t}, g_{t}\right.$, $\left.\hat{h}_{t+1}^{f}, \hat{h}_{t+1}^{m}, \hat{V}_{t}, \hat{c}_{t}^{m}, \hat{c}_{t}^{f}, \Theta_{t}, \hat{e}_{t}^{f}, \hat{e}_{t}^{m}, n_{t}\right\}$ satisfying the conditions given in Appendix A for $t=0 \ldots \infty$.

Along a balanced growth path, we suppose that all exogenous variables are constant:

$$
p_{t}^{f}=p^{f}, \quad p_{t}^{m}=p^{m}, \quad w_{t}^{f}=w^{f}, \quad \text { and } w_{t}^{m}=w^{m}, \quad \forall t \geq 0 .
$$

The stationary variables $\left\{\theta_{t}, \hat{y}_{t}, g_{t}, \hat{h}_{t+1}^{f}, \hat{h}_{t+1}^{m}, \hat{V}_{t}, \hat{c}_{t}^{m}, \hat{c}_{t}^{f}, \Theta_{t}, \hat{e}^{f}, \hat{e}^{m}, n_{t}\right\}$ are constant, which implies that the original variables $h_{t}^{f}, h_{t}^{m}, c_{t}^{m}, c_{t}^{f}, e^{f}, e^{m}$ grow at rate $g \in \mathbb{R}$ and $V$ grows at rate $(1-\sigma) g$.

\subsection{Exogenous Bargaining Power}

Different types of dynamic paths are possible, depending on which constraint binds. We first focus on a situation where the constraint

$$
n_{t} \leq \frac{p_{t}^{f}}{\phi}
$$

binds with equality, i.e., women spend all their time at having and raising children. We start by analyzing the simpler case where bargaining power is exogenous, i.e. $\gamma=0$ and $\theta_{t}=\bar{\theta} \forall t \geq 0$. In this case, the only motive to educate children is to provide them with a higher labor income in the future. When the entire female time endowment is devoted to childrearing activities, the motive to educate daughters grounded on higher 
labor market returns fades away. In such a world, the incentive to educate girls is much limited: with human capital not being rewarded on the labor market; its only interest lies in the increase of the bargaining power of daughters in their future couple. However, this motive does not weight here since we have assumed that bargaining power is not influenced by relative human capital. Therefore we will also have in equilibrium

$$
e_{t}^{f}=0
$$

and the first order condition with respect to the education of the girl (11) holds with strict inequality.

Let us stress one important difference with the existing literature. In Becker, Murphy and Tamura (1990) a poverty trap obtains as the consequence of a threshold effect in human capital accumulation. By adding a constant term to equation (5), they obtain an equilibrium with low education and economic stagnation besides the usual sustained growth equilibrium. Here, the mechanism is different: education expenditures on girls are low because it is not worthwhile to invest in female human capital when women do not spend time on the labor market (because fertility is maximum). Moreover, as education expenditures on boys remain positive in this high fertility regime, we obtain sustained growth driven by male human capital accumulation. In this, our results also depart from the BMT model where the economy stagnates in the high fertility-low education regime. We can now characterize the long-run in this case, which we label "Malthusian balanced growth path".

Proposition 1 Assume $\gamma=0$. Along a Malthusian balanced growth path where $n=$ $p^{f} / \phi$ and $e^{f}=0$, income grows at rate

$$
1+g^{M}=\left(\frac{\beta \delta p^{m} w^{m}}{2^{\frac{1-\delta}{\delta}} a\left(\frac{p^{f}}{\phi}\right)^{\epsilon}}\right)^{\frac{\delta}{1-\delta(1-\sigma)}}
$$

Proof in appendix B.

The growth rate depends positively on life expectancy of male workers. This is a standard Ben-Porath (1967) effect where education investment depends positively on the span during which this investment pays. ${ }^{11}$ Not surprisingly, growth depends negatively on

\footnotetext{
${ }^{11}$ This departs from the neutrality result in Hazan and Zoabi (2006) according to which greater longevity has no effect on optimal investment in human capital and thereby nor does it have on growth. The reason we do not find such result follows from our specific functional choice which is such that the
} 
the cost of education $a$. It also depends positively on the cost of rearing children. In countries having higher cost (for example because infant mortality is high), the net number of children per women is lower, which promotes growth per capita.

For this equilibrium to hold in the long-run, two conditions should be met. The first one is

$$
1-\frac{\beta}{2} n^{1-\epsilon}\left(1+g^{M}\right)^{1-\sigma}>0
$$

This condition is necessary and sufficient for the value function to be defined. The second condition is that fertility is indeed constrained by the biological maximum $p^{f} / \phi$, i.e. inequality (14) holds strictly. An analysis of these two conditions is detailed in Appendix $\mathrm{C}$ and leads to the following result.

Proposition 2 Assume $\gamma=0$. Then a malthusian balanced growth path exists if

$$
1>\frac{\beta}{2}\left(\frac{p^{f}}{\phi}\right)^{1-\frac{\epsilon}{1-\delta(1-\sigma)}}\left(\frac{\beta \delta p^{m} w^{m}}{2^{\frac{1-\delta}{\delta}} a}\right)^{\frac{\delta(1-\sigma)}{1-\delta(1-\sigma)}}
$$

Proof in appendix C.

This inequality defines a threshold $\bar{p}^{f}\left(p^{m}\right)$ such that the condition $p^{f}<\bar{p}^{f}\left(p^{m}\right)$ is a necessary condition for the Malthusian balanced growth path to exist. ${ }^{12}$

Four important implications derive from Proposition 2.

- First, low life expectancy for women is associated with the Malthusian regime. If women have more chances to survive, it is more likely that they would be active on the labor market, and this makes girls education worthwhile. Hence, high life expectancy is incompatible with the corner regime, and empowering women by augmenting their survival probability, $p^{f}$, i.e. reducing the survival gap, is promising to escape from the Malthusian regime.

- Second, lowering the cost of children, for example by reducing children mortality, may also help to escape from the Malthusian regime. Shortening the time needed to raise one living child also increases women presence on the labor market and the return to girls' education. Hence, active implementation of policy measures

condition of homothetic preferences of parents with respect to the number and the level of education of their children required to obtain the neutrality result does not hold in our model.

${ }^{12}$ Notice that the function $\bar{p}^{f}\left(p^{m}\right)$ is decreasing in $p^{m}$ under Assumption 1 as it implies the inequality on parameters $1-\delta(1-\sigma)>\epsilon$ to be satisfied. 
aiming at reducing the total parental time requirement per living child are to serve countries trapped in a Malthusian regime.

- Third, we observe that female wage, $w^{f}$, does not intervene in these conditions. Since women do not participate to the labor market, the possible wage they could earn is irrelevant. Acting on the wage gap is of no help.

- At last, the parameter driving societal and institutional gender equality $\bar{\theta}$ does not appear in the above condition. From this, we may conclude that, in the event of initial gender inequality in social institutions, empowering women by reducing the social and institutional gap $\bar{\theta}$ toward a balanced level does not allow to escape from the Malthusian regime. It would only allow women to enjoy a larger share of household consumption.

\subsection{Endogenous Bargaining Power}

We now lift the assumption of exogenous bargaining power and readdress the condition for the Malthusian equilibrium to prevail. With $\gamma \neq 0$, the bargaining power is a function of the relative human capital levels of the spouses as described by expression (3). For the Malthusian BGP to prevail in this context we need the education on girls to be nil, requiring (11) to hold with strict inequality. Once $h^{f}=e^{f}=0$, we are back to the previous case with exogenous bargaining power as we have from expression (3):

$$
\theta=(1-\gamma) \bar{\theta}+\gamma \frac{\left(h^{m}\right)^{\mu}}{\left(h^{m}\right)^{\mu}+\left(h^{f}\right)^{\mu}}=(1-\gamma) \bar{\theta}+\gamma
$$

Let us now find a condition under which the above is true. For (11) to hold with strict inequality, a sufficient condition is that $\partial\left(1-\theta_{t+1}\right) / \partial e_{t}^{f}$ in (13) is equal to zero (recall that the upper bound on fertility is binding, $\left.n=p^{f} / \phi\right)$. At low level of human capital, this requirement of a nil effect of education on future bargaining power is satisfied under the following condition.

Proposition 3 If the conditions of Proposition 2 are met in addition to

$$
\mu>1 / \delta
$$

The Malthusian corner Equilibrium is a balanced growth path of the model with $\gamma>0$.

Proof in Appendix D. 
Stated differently, when human capital is very low and $\mu>1 / \delta$, bargaining power is insensitive to human capital. As a result, $e^{f}=0$ in equilibrium as both motive to educate girls vanishes (no labor market return and no bargaining power distribution effect). The model becomes thus closer to the unitary model of the family. This latter seems thus more defendable when it represents economies in the corner regime, than when in the interior regime.

\section{Modern Growth Equilibrium}

\subsection{Theory with Exogenous Bargaining Power}

Carrying out the case with exogenous gender power $\left(\theta\right.$ exogenous; $\gamma=0$ and $\theta_{t}=\bar{\theta} \geq$ $0 \forall t$ ), we now focus on the interior regime with positive education on boys and girls (i.e. regime in which all the expressions in (7) hold as strict inequalities).

Along a balanced growth path, human capital of both men and women grow at the same rate $g$. The steady state is a vector $\left\{\theta, \hat{y}, \hat{h}^{f}, \hat{h}^{m}, g, \hat{V}, \hat{c}^{f}, \hat{c}^{m}, \Theta, \hat{e}^{f}, \hat{e}^{m}, n\right\}$ satisfying the system of equations in Appendix E.

We can simplify this system and obtain a balanced growth path characterized by $\left\{g, \hat{e}^{m}, \hat{e}^{f}\right.$, $n$ \} satisfying:

- The equality between the marginal return to education for boys and girls:

$$
p^{m} w^{m}\left(\hat{e}^{m}\right)^{\delta-1}=\left(p^{f}-\phi n\right) w^{f}\left(\hat{e}^{f}\right)^{\delta-1}
$$

- The equality between the marginal return and cost of education for boys:

$$
a n^{\epsilon}=\beta(1+g)^{-\sigma} p^{m} w^{m} \delta\left(\hat{e}^{m}\right)^{\delta-1}
$$

- the equality between the marginal cost and benefit of children:

$$
\begin{aligned}
& {\left[\frac{a}{2}\left(\hat{e}^{f}+\hat{e}^{m}\right)(1+g)+\phi w^{f}\left(\hat{e}^{f}\right)^{\delta}\right] } \\
= & \frac{(1-\epsilon) \beta}{(1+g)^{\sigma-1} n^{\epsilon}-\frac{\beta}{2} n}\left[\left(p^{f}-\phi n\right) w^{f}\left(\hat{e}^{f}\right)^{\delta}+p^{m} w^{m}\left(\hat{e}^{m}\right)^{\delta}-a(1+g)\left(\hat{e}^{f}+\hat{e}^{m}\right) \frac{n}{2}\right]
\end{aligned}
$$


- The definition of the growth rate

$$
2(1+g)=\left(\hat{e}^{f}\right)^{\delta}+\left(\hat{e}^{m}\right)^{\delta}
$$

We have then the following result.

Proposition 4 Along a balanced growth path in the interior regime, the vector $\left\{g, \hat{e}^{m}, \hat{e}^{f}\right.$, $n\}$ does not depend on $\bar{\theta}$.

The social and institutional gap $\bar{\theta}$ does not matter for fertility and education decisions, it only affects the allocation of consumption in the couple. The effect of the other gaps on the interior BGP unfortunately cannot be assessed in general. Indeed, unlike the previous case, we cannot obtain closed form solutions. Applying the implicit function theorem to the system described above to get comparative static results would also be too much involved. Therefore, in the subsequent subsection, we rely on numerical simulations to investigate some properties of this equilibrium.

\subsection{Additional Results from Numerical Analysis}

This section provides a numerical illustration of the model. The simulation exercise points at evaluating the effect of changes in exogenous variables on the long run interior equilibrium. Recognizing the enhancing role of the demographic transition toward low fertility for transition to a modern growth regime central, we will especially look at the impact of shifts in the exogenous variables on fertility.

\section{Calibration}

At this stage, we do not aim at reproducing the demographic transition in a particular country. The evaluation of the model in terms of its empirical implications using crosscountry data is the object of a subsequent section. Still, we choose parameters so as to reflect realistic values that would characterize a stylized industrialized economy along its balanced growth path. More specifically, we proceed in two steps. A first set of parameters and exogenous variables are fixed to keep in line with their accredited values in the macro literature. The remaining free parameters are then chosen so as to generate a number of assumptions on empirical moments featuring our benchmark model.

The model is calibrated under the assumption that a period lasts for 30 years. As our starting set of simulations assumes exogenous intra-household welfare weights, we set 
$\gamma=0$. As a result, the social and institutional parameter $\bar{\theta}$ strictly determines the intra-household distribution of power and we fix it to be equal to 0.5. The altruism elasticity with respect to the number of children embodied in the parameter $\epsilon$ is set equal to $1 / 3 .{ }^{13}$ According to our model specification, the parameter $\sigma$ is the inverse of the inter-temporal elasticity of substitution. We choose a value of 0.34 for it so that Assumption 1 holds. Regarding the time cost parameter $\phi$ associated to children, we follow De la Croix and Doepke (2003) and choose $\phi=0.075$. The parameter $a$ is a scale parameter used to normalize education expenditures with respect to the production level. We set $a=0.1$. In order to reflect the longer life-expectancy of women with respect to that of men observed in most industrialized countries, we fix $p^{f}=1$ and $p^{m}=0.9$.

The remaining set of parameters are pinned down by considering the following scenario. First, we assume identical levels of human capital for men and women. Second, output growth per capita is set at 1.5 percent per year. To tally with observed fertility rates close to the replacement level in many industrialized countries, we impose two children per household. Moreover, the education expenditure-GDP ratio is set at 0.06. The above set of assumptions enables us to pin down four parameters: the elasticity of education in human capital production, the female and male wage rates, and the discount factor. They, respectively, take the following values: $\delta=0.444, w^{f}=5.358, w^{m}=5.060$, and $\beta=0.127$. The higher wage rate for women is required to obtain equal investment in human capital despite lower female labor supply.

\section{Simulations results with exogenous bargaining power}

The purpose here is to analyze how fertility and other characteristics of the economy adjust to changes occurring along our various dimensions of gender inequality. More specifically, we look at the impact of changes in the female wage rate, and in the female total time endowment.

First, we consider the impact of changing relative wages by considering improvements in the female wage rate while keeping that of gender counterpart constant. The results, displayed in Figure 2, indicate that an upward shift in the wage rate of women relative to that of men has a fertility moderating effect. Households exploit the rise in the female labor wage by reducing the number of children, and thereby, freeing up time to mothers for a larger labor market supply. Education in both gender group increases as parents substitutes quality for quantity in the quantity-quality trade-off with respect to

\footnotetext{
${ }^{13}$ Doepke (2005) provides a sensitivity analysis of the Barro - Becker model to this parameter.
} 

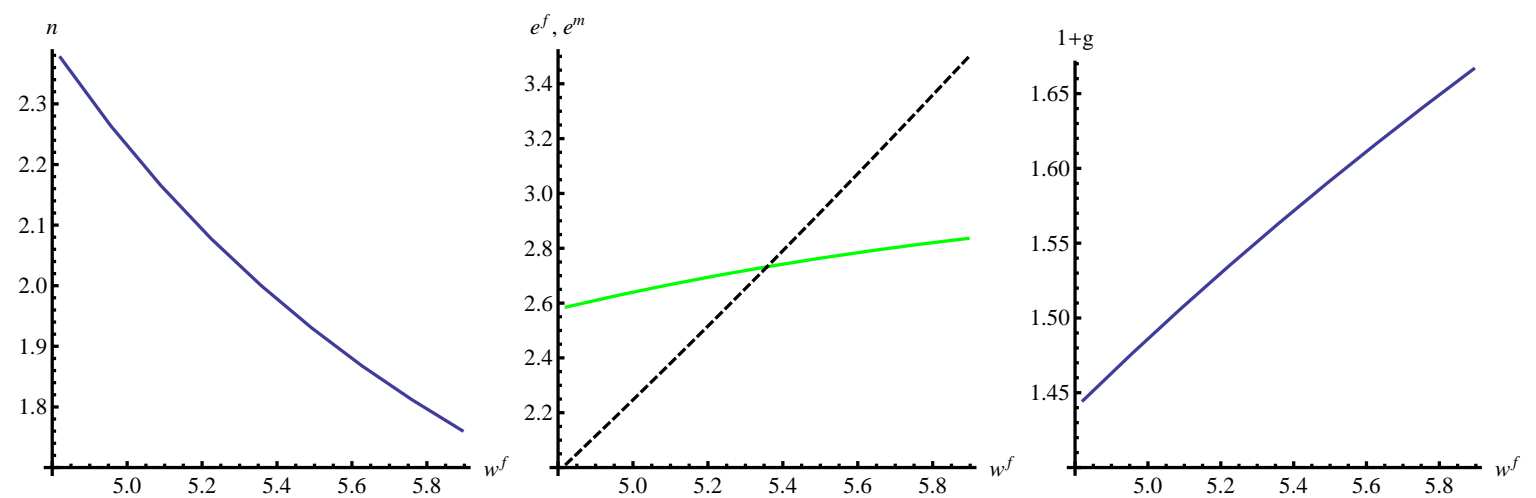

Figure 2: Effect of $w^{f}$ on fertility $n$, Education $e^{f}$ (dash) and $e^{m}$, and growth
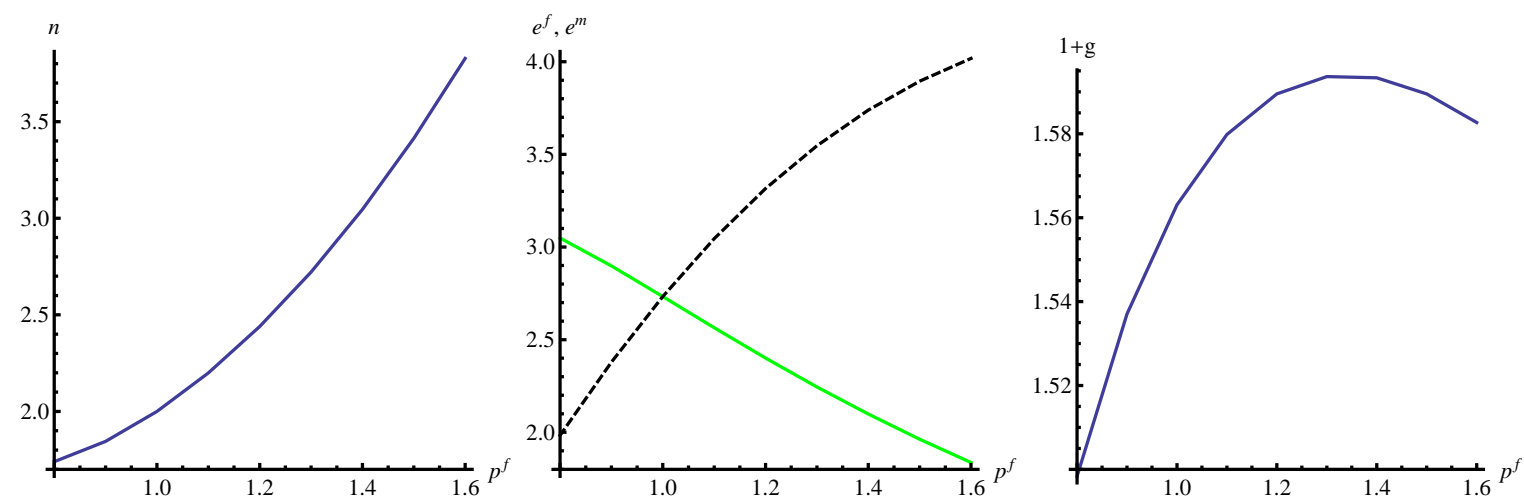

Figure 3: Effect of $p^{f}$ on fertility $n$, Education $e^{f}$ (dash) and $e^{m}$, and growth

the offspring. However, the increase is much steeper for girls due to the improved labor market return on the investment in female human capital. Lower fertility and higher education have an enhancing effect on growth.

The next numerical exercise evaluates the effect of a improvement in the female life expectancy. As depicted in Figure 3, a positive link with both the demand for children and the girl's education obtains. With a longer time span, women can have more children along with an extended labor supply. The latter in turn promotes the labor market reward on girl's education spending. Conversely, parents reduce the amount of education spending on boys with as result a female-to-male catching-up. Finally, observe that improvements in female longevity has a positive effect on growth through its impact on the female labor supply. There is however a turning point beyond which the higher fertility effect overrides the labor market effect and by that reduces growth. ${ }^{14}$

\footnotetext{
${ }^{14}$ A similar hump-shaped pattern is obtained without exogenous fertility in Boucekkine, de la Croix and Licandro, 2002).
} 
Before closing this section, it is worth commenting on the impact of choosing different values for the elasticity of inter-temporal substitution in the utility function. Indeed, the parameter $\sigma$ affects the intra-household distribution of consumption. To see this, reconsidering it as a measure of risk aversion might be enlightening. A higher $\sigma$ or a higher coefficient of risk aversion implies a willingness to distribute resources more equally between the spouses. Indeed, recall from equation (9) that the effective intrahousehold distribution depends on the value of $\sigma$. A smaller $\sigma$ exacerbates the imbalance in the intra-household distribution of resources between the spouses. In our numerical illustration, letting $\bar{\theta}$ evolves from 0.45 to 0.55 has different implications for the effective intra-household distribution, $\Theta$, whether $\sigma=0.34$ or $\sigma=0.5$. In the former case, $\Theta$ ranges from 0.35 to 0.64 , while in the latter case, $\Theta$ evolves in a narrower band, from 0.40 to 0.60 . That is, in the $\sigma=0.5$ case, intra-household distribution of consumption is less unequal compared to the benchmark case with $\sigma=0.34$. Beside affecting the intra-temporal allocation of resources, the parameter $\sigma$ also affect the inter-temporal allocation of resources.

Figure 4 contrasts simulations results for the cases $\sigma=0.34$ and $\sigma=0.5$. For instance, we can see in the left panel that setting $\sigma=0.50$ exacerbates the impact of a change in the female wage rate on fertility: when the wage rate is set to vary from 0.9 percentage points to 1.1 percentage points of its initial value, the fertility drop is much sharper in the $\sigma=0.5$ case. Even more compelling are the different fertility response patterns to improving female longevity depending on the value of $\sigma$. The income effect in the demand for children dominates when the inter-temporal elasticity of substitution is large $(\sigma=0.34)$. Contrastingly, when the elasticity of inter-temporal substitution is low $(\sigma=0.5)$, the demand for children first decreases and then shifts upwards. The initial decrease results from the fact that parents choose to increase the amount of education on girls substantially, which in turn augments the opportunity cost of having children. After some threshold, the income effect overrides the substitution effect in the demand for children and fertility starts swelling.

\section{Simulations results with endogenous bargaining power}

Proceeding to the numerical evaluation of the model with endogenous gender power requires us to revise the parametrization. This is done by dropping the assumption of $\gamma=0$ and setting $\gamma=0.1$ instead (a conservative value not to overestimate the effect of endogenous bargaining power). Recall from expression 3 that parameter $\mu$ is a sensitivity measure of the bargaining power distribution with respect to relative human 

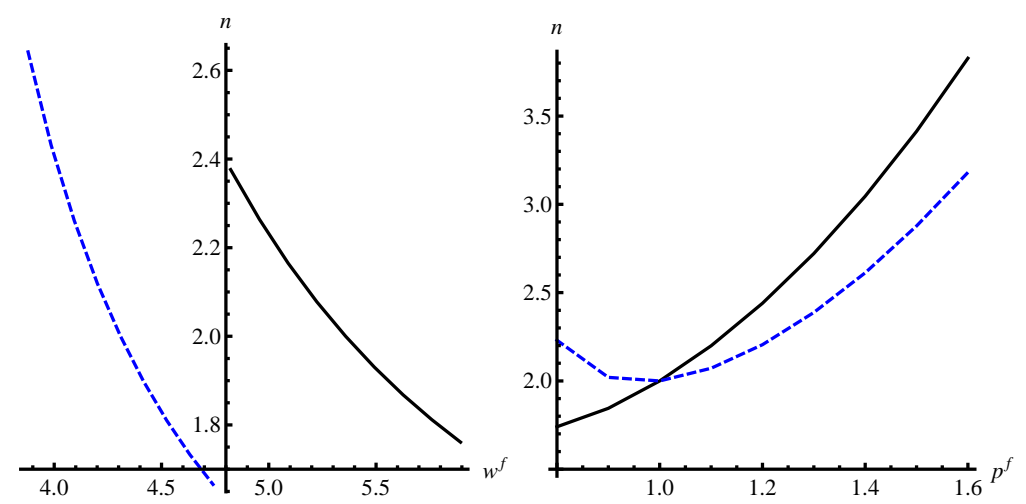

Figure 4: Effects of $w^{f}$ and $p^{f}$ on fertility for $\sigma=0.34$ (solid) and $\sigma=0.5$ (dash)

capital. We set this parameter to be equal to 2. Given these changes, we obtain new calibrated values for the female and male wage rates $\left(w^{f}=6.183\right.$ and $\left.w^{m}=5.839\right)$ and for the elasticity of education $(\delta=0.388)$. The discount factor remains unchanged $(\beta=0.127)$.

From a theoretical perspective, the main effect of adding the endogenous bargaining power specification in the model is to introduce a further motive to educate children in the head of parents: besides the traditional labor market return on the investment in human capital, parents now also ascribe to it an "intra-household market return" formulated in terms of enhanced intra-household bargaining power.

This effect is distinctly evidenced in our first next numerical experiment in which an increase in the social and institutional parameter $\bar{\theta}$ is considered. With this parameter capturing the exogenous dimensions of bargaining power determination, the experiment amounts at analyzing a favorable exogenous shift in the bargaining power of men (see equation (3)). Figure 5 depicts the shifts in the equilibrium values of the model variable following an increase of $\bar{\theta}$ from to 0.45 to 0.55 . Highly noteworthy are the educational gender gap overturn and the fertility increase. Subsequently to an exogenous amelioration of the bargaining position of men, parents take to augment education spending on boys in order to grasp their future utility gain associated to it. However, this is done to the detriment of girls education and, as a result of the impaired labor market return associated to lower female human capital, households choose to increase the number of children and to reduce the labor market time of women. These shifts are negative for growth.

Hereunder, two additional numerical experiments are considered. We first consider the impact of an increase in the female wage rate on the equilibrium values of the model 

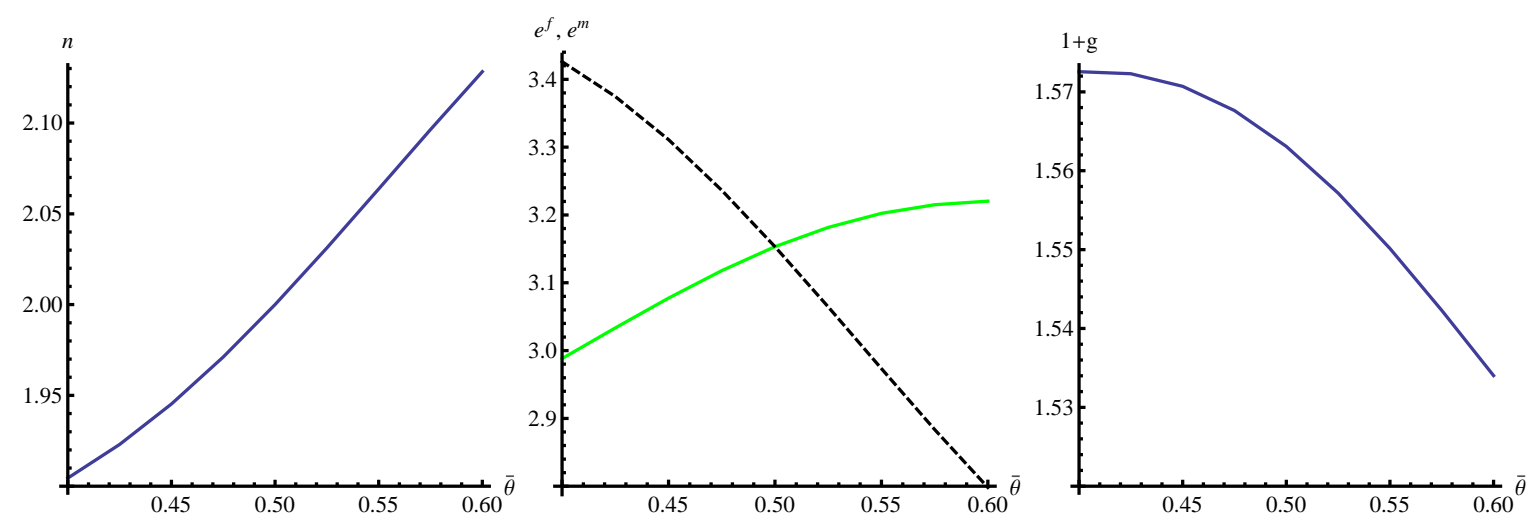

Figure 5: Effect of $\bar{\theta}$ on fertility $n$, Education $e^{f}$ (dash) and $e^{m}$, and growth

variable. The shifts in variable show similar directions with respect to our previous analogous experiment in the $\theta$ exogenous case. We again find that an improvement in the female wage rate leads to a lower number of children per household who however get more education on average, as well as to a stronger growth rate. In our last numerical experiment, we assess the impact of an improvement in the female life expectancy on the benchmark model equilibrium when $\theta$ is endogenously determined. Consistently with the exogenous bargaining case, we find that fertility increases, the education gap decreases, and growth fasten.

Hence, contrary to the exogenous bargaining case, we find that a move of the social and institutional gap $\bar{\theta}$ in favor of women incites parents to invest in girls' education, which leads to a reduction in fertility and promotes growth. The other comparative static results are not much affected by the endogeneity of bargaining power.

\section{Empirical Analysis}

A number of predictions are obtained from the above theoretical model. Economies can be in a Malthusian corner regime with high gender inequality in education and high fertility or in an interior regime. The conditions to be in either regime depend on model parameter values like $p^{f}$ (women life expectancy) and $\phi$ (child rearing time cost). In the Malthusian regime, fertility is perfectly correlated with maximum fertility $p^{f} / \phi$. Neither a narrower social and institutional gap nor a higher wage of women (closing the wage gap) affect fertility in this regime. On the contrary, in the interior regime, countries with more social and institutional gender parity and/or with more balanced wages should display lower fertility and faster growth. In this section we take up evaluating empirically the 
pertinence of the model using cross-country data. The main data sources are briefly outlined and a description of the empirical strategy and associated results follows.

\subsection{Data}

This study examines the relationship between gender equality in its various dimensions and fertility for a sample of 157 countries. The data used are listed in Appendix F. Unless stated otherwise, data refer to the year 2005. Country specific fertility rates are computed from data on number of births per women published by the World Bank in its World Development Indicators. This same source of information provides us with a first indicator on education gender gap by country. It is measured as the girls-to-boys primary completion ratio. As a second indicator, we refer to the Global Gender Gap educational attainment subindex 2007 compiled by the World Economic Forum. It is obtained as a weighted combination of the ratios of women-to-men enrolment in primary-, secondary-, and tertiary-level education and of the women-to-men adult literacy rates. Wherever needed in our computations, survival probabilities are from life tables downloaded from the World Health Organization's website.

\subsection{Methodology, Cross-country evidence and related results}

\section{The maximum net fertility rate}

It is shown in Section 2 that a low female survival probability as well as an extensive fixed time cost per surviving child, possibly due to high infant mortality, are more likely to be archetypal of countries trapped in the Malthusian regime. Let us first define the maximum net fertility rate that captures the maximum number of living children a women consistently can have over her entire fecund life-span. This concept of maximum

net fertility is contingent upon the overall health condition in a society: in a country with high infant mortality and short fecund reproductive period for women (due to low female life expectancy for instance), the maximum number of surviving children that a woman can possibly give birth to will be smaller compared to that in a country that does not confront such sharp problems of infant and adult mortality. From this, we define, country by country, an upper frontier on the maximum number of living children per woman and we then gauge how close to this frontier is the observed number of children per woman. For ease of exposition, we henceforth term the difference between maximum net fertility and actual fertility, the "fertility margin". Consequently, a country which 
has a fertility margin approaching zero is a country in which observed fertility is high given the overall prevailing health and survival conditions.

Getting to the specifics of the evaluation approach, we assume that the adult period lasts for 20 years. The maximum net fertility is computed as the ratio of the expected numbers of years a 20-years-old woman will live over a 20 years long period $\left(p^{f}\right.$ in our model) over the total time cost associated to every surviving child ( $\phi$ in the model). Formally, maximum net fertility, $\bar{n}$, writes as follows:

$$
\bar{n}=\frac{p^{f}}{\phi}=\frac{(L 40 f / L 20 f) * 20}{[a /(1-I M R)]+b},
$$

where $L 20 f$ and $L 40 f$ represent the proportion of women surviving to age 20 and 40 respectively. Hence, the distance ratio $L 40 \mathrm{f} / L 20 \mathrm{f}$ produces the fraction of 20 years old women that effectively reach the age of 40. Multiplying this figure by 20 produces the average number of years a women entering adulthood may expect to live.

The denominator captures the net parental time cost per surviving children with lowercase $a$ standing for the fraction of time spent by a mother at raising each newborn child during her first year of life and $b$ representing the additional time cost associated to surviving children. The term $1-I R M$ is the proportion of newborns that survive the first year of life. Infant mortality rates are directly available from survival table. To fix the value of parameters $a$ and $b$, we follow the methodology presented in Bar and Leukhina (2008). The authors introduce the ratio of the total parental time cost of a surviving child over that of a non surviving child and set it to be equal to four, i.e. $(a+b) / a=4 .^{15}$ This equation combined to the expression of net parental time cost per surviving children,

$$
\phi=\frac{a}{1-I M R}+b,
$$

forms a system that can be solve for $a$ and $b$. In order to do so, we set $I M R=0.04$ (sample average). In addition, referent to the discussion in De la Croix and Doepke (2003), it is supposed that the opportunity cost of a child is equivalent to about 15 percent of the mother's total time endowment and that children live with parents for 15 years. This allows us to set $\phi=0.15 * 15=2.25$. This given, we obtain $a=0.5567$ for the time cost per newborn child, and $b=1.6701$ as the additional cost per children that effectively reach adult age. By way of example, Table 2 reports the computational steps of the maximum net fertility for the countries of Iran, Mexico and Mozambique.

\footnotetext{
${ }^{15}$ See Bar and Leukhina (2008) for a detailed explanation on the calibration strategy of this ratio. It is done by using the data on age-specific mortality and the assumption that the instantaneous cost function of raising a child is a decreasing linear function of the childs age.
} 


\begin{tabular}{lccccccccc}
\hline \hline & L20f & L40f & $p^{f}$ & 1-IMR & $\phi$ & $\bar{n}$ & $n$ & $\bar{n}-n$ & $e^{f} / e^{m}$ \\
\hline Iran & 0.96 & 0.94 & 19.58 & 0.97 & 2.27 & 8.63 & 2.00 & 6.56 & 0.96 \\
Mexico & 0.97 & 0.96 & 19.70 & 0.98 & 2.26 & 8.70 & 2.06 & 6.60 & 0.99 \\
Mozambique & 0.83 & 0.55 & 13.30 & 0.90 & 2.31 & 5,75 & 4.77 & 0.45 & 0.75 \\
\hline \hline
\end{tabular}

Table 2: Maximun Net Fertility: Iran, Mexico and Mozambique

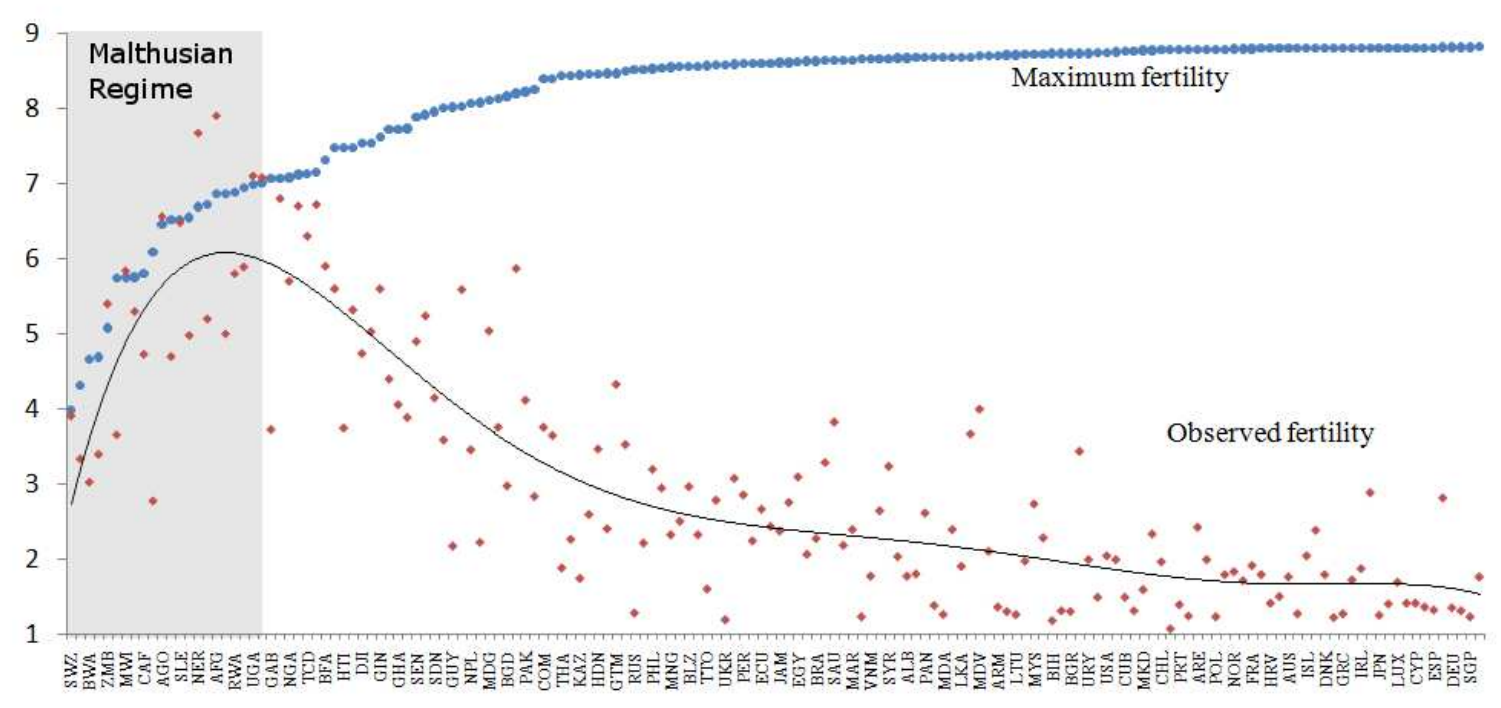

Figure 6: The fertility margin : Cross-Country Data

We see that, given the parameter choice and the countries' data on survival rates, a woman devoting all her time at raising children could have over 8 living children in Iran and Mexico but only somewhat fewer than 6 children in Mozambique. In the next to last column, we report the fertility margin, $\bar{n}-n$, with $n$ being the observed number of living children per women. It is computed as the number of birth per women form the World Development Indicators adjusted for the infant mortality rate associated to first year of life.

Interestingly, Mozambique is the country for which the distance between actual fertility and maximum net fertility rates is the tiniest. That is, despite having the lowest maximum net fertility, due to the low female survival rate and the high cost of having living children, Mozambique has the highest fertility rate out of the three countries. As a result, we can say that this country has a fertility rate that is bigger both in absolute and relative terms (i.e. in distance terms). Contrastingly, compared to Iran, Mexico presents a larger fertility rate in absolute terms but in relative terms, fertility is smaller 
(the fertility margin is larger).

Figure 6 displays the fertility margin for our list of countries sorted in ascending order along the maximum net fertility variable. As we move from left to right along the $\mathrm{x}$-axis, maximum net fertility and observed number of living births per women first increase alongside up to some break point beyond which the distance between the two variables start to widen. This provides us with a good illustration of what constitutes the essence of Proposition 2: countries with high infant mortality and low female life expectancy (resulting in a low maximum net fertility) are more likely to be trapped in the Malthusian regime. In Figure 6, we indeed observe that those countries with a lower $\bar{n}$ also tend to display a smaller fertility margin, $\bar{n}-n$ with respect to countries that enjoy a larger $\bar{n}$ due to longer female life expectancy and lower infant mortality rates.

To provide a further evidence that, in countries in the Malthusian regime, fertility is constrained by the supply side, we categorize countries into Malthusian regimes and non-Malthusian ones. Fixing our separation criterion to a fertility margin equal to 2 standard deviations, we find that 21 countries can be listed in the Malthusian regime category. In other words, for 21 countries, we observe a difference between our computed maximum net fertility variable and effective fertility lower than 2 standard errors. All other countries present a bigger positive distance between maximum net and effective fertility. Within the Malthusian regime category, we compute the correlation between fertility and maximum fertility. It equals 0.85 which is not significantly different from 1.

\section{Fertility, and gender power}

In Table 3, we correlate our measure of fertility margin with distinct measures of the gender gap. The first row shows these correlations for the entire cross-country sample. In line with a well established result, we observe strong positive relationship between gender equality in education and low fertility margin. ${ }^{16}$ Noticeably, fertility margin relates less strongly to the other dimensions of the gender gap. However, interesting patterns in these correlations emerge when we consider the two groups of countries. We observe that in the Malthus group, no correlation is significant. This is perfectly in line with the model, where the fertility margin is always equal zero in this regime. In the non-Malthus (interior) group of countries, correlations with the various dimensions are always stronger than in the full sample. Beyond the strong correlation between the gender gap in education and our measure of fertility margin, we find a positive

\footnotetext{
${ }^{16}$ See for instance Klasen (2002), and Dollar and Gatti (1999).
} 
correlation with our two measures of women political power. If we accept them to be an indicator of the social and institutional gender gap, we may assert that reducing the gender gap along this dimension would help to fasten the demographic transition. This concords with our result from Section 3 when bargaining power is endogenous. In a similar vein, the correlation between fertility margin and the economic participation and opportunity gender gap index is positive. Considering that the female-to-male wage gap is an important built-in factor for this gender equality index ${ }^{17}$, we may allege that the positive relationship goes in line with our result according to which a lower gender gap is fertility reducing and growth enhancing for economies in the interior regime (see Figure 3).

\begin{tabular}{l|cc|c}
\hline \hline & $\begin{array}{c}\text { Educational } \\
\text { Attainment }\end{array}$ & $\begin{array}{c}\text { Education } \\
\text { gap (WDI) }\end{array}$ & $\begin{array}{c}\text { Economic particip. } \\
\text { and opportunity }\end{array}$ \\
\hline All Countries & $0.658(0.00 ; 126)$ & $0.490(0.00 ; 101)$ & $0.128(0.15 ; 126)$ \\
Malthus & $0.048(0.88 ; 11)$ & $0.136(0.58 ; 17)$ & $0.174(0.57 ; 11)$ \\
Interior & $0.685(0.00 ; 113)$ & $0.518(0.00 ; 82)$ & $0.367(0.00 ; 113)$ \\
\hline & Political & Women in & \\
& Empowerment & Parliament (U.N.) & \\
All Countries & $0.163(0.07 ; 126)$ & $0.174(0.03 ; 157)$ & \\
Malthus & $-0.250(0.41 ; 11)$ & $0.028(0.90 ; 19)$ & \\
Interior & $0.202(0.03 ; 113)$ & $0.275(0.00 ; 136)$ & \\
\hline \hline
\end{tabular}

p-value and degrees of freedom ( $\mathrm{N}$ obs-2) between parentheses.

Table 3: Correlations with fertility margin

\section{Conclusion}

Endorsed by all world's leading development institutions, the promotion of gender equality has become a race horse toward sustainable development in all regions of the world. In spite of the surrounding consensus on the positive link between gender equality and

\footnotetext{
${ }^{17}$ In the construction of the "Economic Participation and Opportunity gender equality index", the World Economic Forum attributes a weight of 0.310 to the female-over-male wage ratio (for similar work). The second main component is the ratio of estimated female earned income over male value with a weight of 0.221 . The other factors are the ratio of female labor force participation over male value, the ratio of female legislators, senior officials and managers over male; and the ratio of female professional and technical workers over male value
} 
economic growth, macroeconomic studies that formally explore the role of gender heterogeneity remain relatively sparse. In this paper, we try to formally clarify the part played by various dimensions to gender inequality in fostering the transition toward faster growth. Fully recognizing the economic growth enhancing impact of a reduced population growth, we especially focus on the pathways by which increases in gender equality may affect fertility.

To this end, we set up an overlapping-generations model with gender heterogeneity, endogenous fertility, and parental investment in children's human capital. Distinctive to our model is the specification of a household decision process based on the notion of intra-household bargaining power. In this setting we are able to identify four dimensions of gender equality (life expectancy-, wage-, socio-institutional-, and education-based inequality concepts), and to analyze their impact on both demographic and economic outcomes.

We first characterize two equilibrium regimes: a Malthusian corner regime with low growth, high fertility and strong gender inequality in education; and an interior growth regime in which low fertility and a more balanced distribution of education between men and women prevail.

We next derive the condition to escape the Malthusian regime. Reducing the social and institutional gender gap in economies trapped in the Malthusian regime does not prove to be the way out. Nor is lowering the gender wage gap. The key policy measures to ease out these countries are to promote female longevity and infant survival rates. These findings are corroborated in our cross-country data analysis where evidence is found that countries with high infant mortality and low female life expectancy are more likely to be trapped in the Malthusian regime. In addition, for countries that we identify as falling in the "Malthusian regime" category, the distance between maximum and observed fertility exhibits weak correlations with the various dimensions of gender equality.

We further our understanding of how fertility and other characteristics of the economy adjust to changes in gender equality by proceeding to some numerical simulations of the benchmark interior regime. When bargaining power is exogenous, augmenting the female wage rate relative to that of men abates fertility and fosters growth. We also find that improving female life expectancy is positive for growth. When bargaining power is endogenous, the sole additional result comes with our social and institutional gender gap: the implementation of policy measures aiming at stronger gender parity in the social and institutional set-up of a given economy in the interior regime will promote economic growth by lowering the population growth rate. 
Let us close by insisting on the fact that, as unsettling as may sound our result according to which reducing the social and institutional is of no immediate help to escape the high fertility regime in low income countries, we do not discard the importance of achieving gender parity. To start with, it is certainly a worthy objective in itself. More work needs to be done in order to obtain a clear understanding of the mechanisms linking gender equality and economic growth. The present work is one step ahead in this direction. 


\section{A Dynamics with stationary variables}

Given initial conditions $\left(h_{0}^{f}, h_{0}^{m}\right)$, an equilibrium trajectory is a vector $\left\{\theta_{t}, \hat{y}_{t}, g_{t}, \hat{h}_{t+1}^{f}\right.$, $\left.\hat{h}_{t+1}^{m}, \hat{V}_{t}, \hat{c}_{t}^{m}, \hat{c}_{t}^{f}, \Theta_{t}, \hat{e}^{f}, \hat{e}^{m}, n_{t}\right\}$ satisfying the following conditions for all $t \geq 0$.

$$
\begin{aligned}
& \theta_{t}=(1-\gamma) \bar{\theta}+\gamma \frac{\left(\hat{h}_{t}^{m}\right)^{\mu}}{\left(\hat{h}_{t}^{m}\right)^{\mu}+\left(\hat{h}_{t}^{f}\right)^{\mu}}, \\
& \hat{y}_{t}=\left(p_{t}^{f}-\phi n_{t}\right) w_{t}^{f} \hat{h}_{t}^{f}+p_{t}^{m} w_{t}^{m} \hat{h}_{t}^{m}-a\left(\hat{e}_{t}^{f}+\hat{e}_{t}^{m}\right) \frac{n}{2}, \\
& \left(1+g_{t}\right) \hat{h}_{t+1}^{i}=\left(\hat{e}_{t}^{i}\right)^{\delta} \text {, } \\
& \hat{h}_{t}^{f}+\hat{h}_{t}^{m}=2 \text {, } \\
& \hat{V}_{t}=\left(1-\theta_{t}\right) \frac{\left(\hat{c}_{t}^{f}\right)^{1-\sigma}}{1-\sigma}+\theta_{t} \frac{\left(\hat{c}_{t}^{m}\right)^{1-\sigma}}{1-\sigma}+\frac{1}{2} \beta n_{t}^{1-\epsilon}\left(1+g_{t}\right)^{1-\sigma} \hat{V}_{t+1}, \\
& \hat{c}_{t}^{m}=\Theta_{t} \hat{y}_{t}, \\
& \hat{c}_{t}^{f}=\left(1-\Theta_{t}\right) \hat{y}_{t}, \\
& \Theta_{t}=\frac{\theta_{t}^{1 / \sigma}}{\theta_{t}^{1 / \sigma}+\left(1-\theta_{t}\right)^{1 / \sigma}}, \\
& \frac{\theta_{t} a n_{t}^{\epsilon}}{\left(\hat{c}_{t}^{m}\right)^{\sigma}} \geq \beta\left(1+g_{t}\right)^{-\sigma}\left(\frac{\gamma \mu\left(\hat{h}_{t+1}^{f}\right)^{\mu}\left(\hat{h}_{t+1}^{m}\right)^{\mu-1}}{\left(\left(\hat{h}_{t+1}^{m}\right)^{\mu}+\left(\hat{h}_{t+1}^{f}\right)^{\mu}\right)^{2}} \frac{\left(\hat{c}_{t+1}^{m}\right)^{1-\sigma}}{1-\sigma}\right. \\
& \left.+\frac{\theta_{t+1}}{\left(\hat{c}_{t+1}^{m}\right)^{\sigma}} p_{t+1}^{m} w_{t+1}^{m}\right) \delta\left(\hat{e}_{t}^{m}\right)^{\delta-1} \\
& \frac{\left(1-\theta_{t}\right) a n_{t}^{\epsilon}}{\left(\hat{c}_{t}^{f}\right)^{\sigma}} \geq \beta\left(1+g_{t}\right)^{-\sigma}\left(\frac{\gamma \mu\left(\hat{h}_{t+1}^{f}\right)^{\mu-1}\left(\hat{h}_{t+1}^{m}\right)^{\mu}}{\left(\left(\hat{h}_{t+1}^{m}\right)^{\mu}+\left(\hat{h}_{t+1}^{f}\right)^{\mu}\right)^{2}} \frac{()^{1-\sigma}}{1-\sigma}\right. \\
& \left.+\frac{1-\theta_{t+1}}{\left(\hat{c}_{t+1}^{f}\right)^{\sigma}}\left(p_{t+1}^{f}-\phi n_{t+1}\right) w_{t+1}^{f}\right) \delta\left(\hat{e}_{t}^{f}\right)^{\delta-1} \\
& \hat{V}_{t+1} \geq \frac{\theta_{t}}{\left(\hat{c}_{t}^{m}\right)^{\sigma}} \frac{2\left(1+g_{t}\right)^{\sigma-1}}{(1-\epsilon) \beta n_{t}^{-\epsilon}}\left[\frac{a}{2}\left(\hat{e}_{t}^{f}+\hat{e}_{t}^{m}\right)+\phi w_{t}^{f} \hat{h}_{t}^{f}\right] \\
& \hat{e}_{t}^{f}, \hat{e}_{t}^{m} \geq 0 \\
& n_{t} \leq p_{t}^{f} / \phi
\end{aligned}
$$




\section{B Malthusian Growth Rate - Proposition 1}

In deriving the expression for the Malthusian growth rate, $1+g^{M}$, we first use (18) and (19) with $\hat{h}^{f}=0$ so as to express education expenditures on boys in efficient form as a function of the growth rate:

$$
\hat{e}^{m}=\left[2\left(1+g^{M}\right)\right]^{\frac{1}{\delta}}
$$

The growth rate in the Malthusian equilibrium is then derived from the optimality condition with respect to the education of the boys (24). Bear in mind that the first term in the RHS brackets of this condition vanishes as $\gamma=0$ (implying $\partial \Theta_{t+1} / \partial e_{t}^{m}=0$ ) in this regime. Hence, we may write,

$$
\frac{\theta a n^{\epsilon}}{\left(\hat{c}^{m}\right)^{\sigma}}=\beta\left(1+g^{M}\right)^{-\sigma} \frac{\theta}{\left(\hat{c}^{m}\right)^{\sigma}} p^{m} w^{m} \delta\left(\hat{e}^{m}\right)^{\delta-1}
$$

Using $n=p^{f} / \phi$ and $\hat{e}_{t}^{m}=\left[2\left(1+g^{M}\right)\right]^{\frac{1}{\delta}}$, the expression for the Malthusian growth rate is straight to derive:

$$
1+g^{M}=\left(\frac{\beta \delta p^{m} w^{m}}{2^{\frac{1-\delta}{\delta}} a\left(\frac{p^{f}}{\phi}\right)^{\epsilon}}\right)^{\frac{\delta}{1-\delta(1-\sigma)}}
$$

\section{Thresholds Determination - Proposition 2}

We next direct our analysis on the conditions for such an equilibrium to arise.

First, the inequality $1>\frac{1}{2} \beta n^{1-\epsilon}\left(1+g^{M}\right)^{1-\sigma}$ is required to hold in order to obtain a finite objective function. This implies the following restriction:

$$
\begin{gathered}
1>\frac{1}{2} \beta\left(\frac{p^{f}}{\phi}\right)^{1-\epsilon}\left(\frac{\beta \delta p^{m} w^{m}}{2^{\frac{1-\delta}{\delta}} a\left(\frac{p^{f}}{\phi}\right)^{\epsilon}}\right)^{\frac{\delta(1-\sigma)}{1-\delta(1-\sigma)}} \\
\Leftrightarrow 1>\frac{1}{2} \beta\left(\frac{p^{f}}{\phi}\right)^{1-\frac{\epsilon}{1-\delta(1-\sigma)}}\left(\frac{\beta \delta p^{m} w^{m}}{2^{\frac{1-\delta}{\delta}} a}\right)^{\frac{\delta(1-\sigma)}{1-\delta(1-\sigma)}}
\end{gathered}
$$

This defines a threshold $\bar{p}^{f}\left(p^{m}\right)$ such that the condition $p f<\bar{p}^{f}\left(p^{m}\right)$ is a necessary condition for the Malthusian balanced growth path to exist. $\bar{p}^{f}\left(p^{m}\right)$ is a decreasing function of $p^{m}$ assuming $1-\delta(1-\sigma)>\epsilon$, which always holds under Assumption 1 .

Second, as, in the Malthusian equilibrium, the upper bounds on the maximum number 
of children is achieved, $n=p^{f} / \phi$, the optimality condition with respect to the number of children (26) holds as a strict inequality:

$$
\hat{V}>\frac{\theta}{\left(\hat{c}^{m}\right)^{\sigma}} \frac{2\left(1+g^{M}\right)^{\sigma-1}}{(1-\epsilon) \beta n^{-\epsilon}}\left[\frac{a}{2} \hat{e}^{m}\right]
$$

We compute the steady state welfare level $\hat{V}$ using (20):

$$
\left(1-\frac{1}{2} \beta n^{1-\epsilon}\left(1+g^{M}\right)^{1-\sigma}\right) \hat{V}=(1-\theta) \frac{\left(\hat{c}^{f}\right)^{1-\sigma}}{1-\sigma}+\theta \frac{\left(\hat{c}^{m}\right)^{1-\sigma}}{1-\sigma}
$$

Knowing that $\hat{h}^{m}=2$ from (19), income can be derived from (17) as

$$
\hat{y}=2 p^{m} w^{m}-a \frac{n}{2} \hat{e}^{m}
$$

with $n=p^{f} / \phi$. Next, substitute into the expression of $\hat{V}$ the individual demands for private consumption expressed in terms of the net income, $\hat{y}_{t}$, given by (21)-(22). The following equation for the welfare sum is then obtained:

$$
(1-\sigma)\left(1-\frac{1}{2} \beta n^{1-\epsilon}\left(1+g^{M}\right)^{1-\sigma}\right) \hat{V}=k\left[2 p^{m} w^{m}-a \frac{n}{2} \hat{e}^{m}\right]^{1-\sigma}
$$

with

$$
k=(1-\theta)(1-\Theta)^{1-\sigma}+\theta \Theta^{1-\sigma}
$$

Substituting this result into the optimality condition with respect to the number of children and replacing $\hat{c}^{m}$ by its value produces:

$$
\frac{k\left[2 p^{m} w^{m}-a \frac{n}{2} \hat{e}^{m}\right]^{1-\sigma}}{(1-\sigma)\left(1-\frac{1}{2} \beta n^{1-\epsilon}\left(1+g^{M}\right)^{1-\sigma}\right)}>\frac{\theta}{\left(\Theta\left(2 p^{m} w^{m}-a \hat{e}^{m} \frac{p^{f}}{2 \phi}\right)\right)^{\sigma}} \frac{2\left(1+g^{M}\right)^{\sigma-1}}{(1-\epsilon) \beta n^{-\epsilon}}\left[\frac{a}{2} \hat{e}^{m}\right]
$$

which can be simplified into

$$
\frac{k \Theta^{\sigma}}{\theta} \frac{\left[2 p^{m} w^{m}-a \frac{n}{2} \hat{e}^{m}\right]}{1-\frac{1}{2} \beta n^{1-\epsilon}\left(1+g^{M}\right)^{1-\sigma}}>2(1-\sigma) \frac{\left(1+g^{M}\right)^{\sigma-1}}{(1-\epsilon) \beta n^{-\epsilon}}\left[\frac{a}{2} \hat{e}^{m}\right]
$$

Developing the term $\frac{k \Theta^{\sigma}}{\theta}=1$ leads us to conclude that it equals 1 . Since the inequality $1>\frac{1}{2} \beta n^{1-\epsilon}\left(1+g^{M}\right)^{1-\sigma}$ is required to hold in order to obtain a finite objective function, we can rewrite the above inequality condition as

$$
2 p^{m} w^{m}>\left(\left(1+g^{M}\right)^{\sigma-1}-\frac{1}{2} \beta n^{1-\epsilon}\right) \frac{2(1-\sigma)}{(1-\epsilon) \beta n^{-\epsilon}}\left[\frac{a}{2} \hat{e}^{m}\right]+a \frac{n}{2} \hat{e}^{m}
$$


Rearranging terms further leads to:

$$
\frac{4 p^{m} w^{m}}{a n \hat{e}^{m}}>\frac{2(1-\sigma)\left(\left(1+g^{M}\right)^{\sigma-1} n^{\epsilon-1}-\frac{1}{2} \beta\right)}{(1-\epsilon) \beta}+1
$$

Replacing $\hat{e}^{m}$ by its value

$$
\frac{2^{2-\frac{1}{\delta}} p^{m} w^{m}}{a n\left(1+g^{M}\right)^{\frac{1}{\delta}}}>\frac{2(1-\sigma)\left(\left(1+g^{M}\right)^{\sigma-1} n^{\epsilon-1}-\beta / 2\right)}{(1-\epsilon) \beta}+1
$$

For ease of notations, let us define $z \equiv \frac{\beta \delta p^{m} w^{m}}{2^{\frac{1-\delta}{\delta}} a}$. We can then express the growth rate in terms of the following product:

$$
1+g^{M}=\left(z n^{-\epsilon}\right)^{\frac{\delta}{1-\delta(1-\sigma)}}=z^{\frac{\delta}{1-\delta(1-\sigma)}} n^{\frac{-\epsilon \delta}{1-\delta(1-\sigma)}} .
$$

Using this in the above inequality conditions, we get:

$$
\frac{2}{n z^{\frac{1}{1-\delta(1-\sigma)}} n^{\frac{-\epsilon}{1-\delta(1-\sigma)}}} \frac{\overbrace{\beta \delta p^{m} w^{m}}^{=z}}{a 2^{\frac{1-\delta}{\delta}}} \frac{2(1-\sigma)\left[z^{\frac{\delta(\sigma-1)}{1-\delta(1-\sigma)}} n^{\frac{-\epsilon \delta(\sigma-1)}{1-\delta(1-\sigma)}} n^{\epsilon-1}-\beta / 2\right]}{\beta \delta}>\frac{(1-\epsilon) \beta}{(1-\beta},
$$

or equivalently,

$$
\begin{aligned}
& \frac{2}{\beta \delta} \frac{z^{\frac{-\delta(1-\sigma)}{1-\delta(1-\sigma)}}}{n^{\frac{1-\delta(1-\sigma)-\epsilon}{1-\delta(1-\sigma)}}}>\frac{2(1-\sigma)\left[z^{\frac{\delta(\sigma-1)}{1-\delta(1-\sigma)}} n^{\frac{\epsilon \delta(1-\sigma)+(\epsilon-1)(1-\delta(1-\sigma))}{1-\delta(1-\sigma)}}-\beta / 2\right]}{(1-\epsilon) \beta}+1 \\
& \Leftrightarrow \frac{2}{\beta \delta} z^{\frac{-\delta(1-\sigma)}{1-\delta(1-\sigma)}} n^{-\frac{1-\delta(1-\sigma)-\epsilon}{1-\delta(1-\sigma)}}>\frac{2(1-\sigma)\left[z^{\frac{-\delta(1-\sigma)}{1-\delta(1-\sigma)}} n^{-\frac{1-\delta(1-\sigma)-\epsilon}{1-\delta(1-\sigma)}}-\beta / 2\right]}{(1-\epsilon) \beta}+1,
\end{aligned}
$$

which can be rewritten as

$$
\Leftrightarrow \frac{2}{\beta \delta} Z>\frac{2(1-\sigma) Z}{(1-\epsilon) \beta}-\frac{2(1-\sigma) \beta / 2}{(1-\epsilon) \beta}+1,
$$

with $Z=z^{\frac{-\delta(1-\sigma)}{1-\delta(1-\sigma)}} n^{-\frac{1-\delta(1-\sigma)-\epsilon}{1-\delta(1-\sigma)}}$.

Rearranging further the terms produces:

$$
2 Z-\frac{2 \delta(1-\sigma)}{(1-\epsilon)} Z>\beta \delta-\frac{2 \beta \delta(1-\sigma)}{2(1-\epsilon)}
$$




$$
\begin{gathered}
\Leftrightarrow Z-\frac{\delta(1-\sigma)}{(1-\epsilon)} Z>\frac{\beta \delta}{2}\left[1-\frac{(1-\sigma)}{(1-\epsilon)}\right] \\
\Leftrightarrow Z((1-\epsilon)-\delta(1-\sigma))>\frac{\beta \delta}{2}((1-\epsilon)-(1-\sigma)) .
\end{gathered}
$$

Given that $1-\delta(1-\sigma)>\epsilon$ holds under assumption 1 , we can write:

$$
Z>\frac{\beta \delta}{2}\left(\frac{(1-\epsilon)-(1-\sigma)}{(1-\epsilon)-\delta(1-\sigma)}\right)
$$

It is easy to show that the above condition is always satisfied given our inequality requirement such that $1>\frac{1}{2} \beta n^{1-\epsilon}\left(1+g^{M}\right)^{1-\sigma}$ that ensures a finite objective function. We previously showed that this latter requirement translates into the following condition:

$$
\Leftrightarrow \quad 1>\frac{1}{2} \beta\left(\frac{p^{f}}{\phi}\right)^{1-\frac{\epsilon}{1-\delta(1-\sigma)}}\left(\frac{\beta \delta p^{m} w^{m}}{2^{\frac{1-\delta}{\delta}} a}\right)^{\frac{\delta(1-\sigma)}{1-\delta(1-\sigma)}}
$$

Using our previous notations, the above inequality condition reduces to

$$
1>\frac{\beta}{2 Z} \Leftrightarrow Z>\frac{\beta}{2}
$$

A little side calculation indicates us that the the following inequality is satisfied for $\delta<1$

$$
\frac{\beta}{2}>\frac{\beta \delta}{2}\left(\frac{(1-\epsilon)-(1-\sigma)}{(1-\epsilon)-\delta(1-\sigma)}\right)
$$

and, as a direct result, we may conclude that whenever inequality (30) is satisfied, equation (29) holds true as well.

\section{Proof of Proposition 3}

Writing down the first derivative of the bargaining power variable with respect to education and looking at the limit when girls' education goes toward zero gives the following expression:

$$
\lim _{e_{t}^{f} \rightarrow 0} \frac{\partial\left(1-\theta_{t+1}\right)}{\partial e_{t}^{f}}=\frac{\mu\left(h_{t+1}^{m}\right)^{\mu}}{\left[\left(h_{t+1}^{m}\right)^{\mu}+\left(h_{t+1}^{f}\right)^{\mu}\right]^{2}} \delta\left(\bar{h}_{t}\right)^{\mu(1-\delta)}\left(e_{t}^{f}\right)^{\delta \mu-1}
$$


Clearly this expression is equal to zero whenever $\mu \delta-1>0$. Hence $\mu \delta-1>0$ is sufficient to have $e^{f}=0$, which in turn implies exogenous bargaining power.

\section{E Interior BGP with Exogenous Bargaining Power}

$$
\begin{aligned}
\theta & =\bar{\theta} \\
\hat{y} & =\left(p^{f}-\phi n\right) w^{f} \hat{h}^{f}+p^{m} w^{m} \hat{h}^{m}-a\left(\hat{e}^{f}+\hat{e}^{m}\right) \frac{n}{2}, \\
(1+g) \hat{h}^{i} & =\left(\hat{e}^{i}\right)^{\delta} \\
\hat{h}^{f}+\hat{h}^{m} & =2 \\
\hat{V} & =(1-\theta) \frac{\left(\hat{c}^{f}\right)^{1-\sigma}}{1-\sigma}+\theta \frac{\left(\hat{c}^{m}\right)^{1-\sigma}}{1-\sigma}+\frac{1}{2} \beta n^{1-\epsilon}(1+g)^{1-\sigma} \hat{V} \\
\hat{c}^{m} & =\Theta \hat{y}, \\
\hat{c}^{f} & =(1-\Theta) \hat{y} \\
\Theta & =\frac{\theta}{\theta^{1 / \sigma}+(1-\theta)^{1 / \sigma}}, \\
a n^{\epsilon} & =\beta(1+g)^{-\sigma} p^{m} w^{m} \delta\left(\hat{e}^{m}\right)^{\delta-1}, \\
a n^{\epsilon} & =\beta(1+g)^{-\sigma}\left(p^{f}-\phi n\right) w^{f} \delta\left(\hat{e}^{f}\right)^{\delta-1} \\
\hat{V} & =\frac{\theta}{\left(\hat{c}^{m}\right)^{\sigma}} \frac{2(1+g)^{\sigma-1}}{(1-\epsilon) \beta n^{-\epsilon}}\left[\frac{a}{2}\left(\hat{e}^{f}+\hat{e}^{m}\right)+\phi w^{f} \hat{h}^{f}\right]
\end{aligned}
$$

\section{F Data}




\begin{tabular}{|c|c|c|c|c|c|c|c|c|c|c|c|c|c|c|}
\hline \multirow[t]{2}{*}{ Country } & L1 & $\begin{array}{r}\text { L20 } \\
\text { females }\end{array}$ & $\begin{array}{r}\text { L40 } \\
\text { females }\end{array}$ & $\begin{array}{r}\text { Max } \\
\text { net } \\
\text { fertility }\end{array}$ & $\begin{array}{r}\text { Birth } \\
\text { per } \\
\text { woman }\end{array}$ & $\begin{array}{r}\text { Net birth } \\
\text { per } \\
\text { woman }\end{array}$ & $\begin{array}{r}\text { Fertility } \\
\text { margin }\end{array}$ & $\begin{array}{c}\text { Malthus } \\
\text { regime }\end{array}$ & \multirow{2}{*}{$\begin{array}{r}\text { girls/ boys } \\
\text { Primary } \\
\text { Complet. } \\
\text { WDI }\end{array}$} & \multirow{2}{*}{$\begin{array}{r}\text { parliamentary } \\
\text { seats occup. } \\
\text { by women } \% \\
\text { U.N. } \\
\end{array}$} & \multirow{2}{*}{$\begin{array}{r}\text { Economic } \\
\text { Particip. } \\
\text { \& Opport. }\end{array}$} & $\begin{array}{r}\text { Educ. } \\
\text { Attain- } \\
\text {-ment }\end{array}$ & $\begin{array}{r}\text { Health } \\
\text { and } \\
\text { Survival }\end{array}$ & \multirow[t]{2}{*}{$\begin{array}{c}\text { Political } \\
\text { Empow- } \\
\text {-erment }\end{array}$} \\
\hline & World & tealth Ors & nization & Eq.(15) & WDI & \multicolumn{3}{|c|}{ Our computations } & & & & \multicolumn{2}{|c|}{ Vorld Economic Forum } & \\
\hline Swaziland & 89555 & 81800 & 37758 & 4.03 & 3.91 & 3.50 & 0.53 & 1 & 1.06 & 7.76 & & & & \\
\hline Zimbabwe & 93987 & 89262 & 43942 & 4.35 & 3.34 & 3.14 & 1.21 & 1 & 0.95 & 14.40 & 0.604 & 0.925 & 0.952 & 0.105 \\
\hline Botswana & 91434 & 85914 & 46128 & 4.71 & 3.03 & 2.77 & 1.94 & 1 & & 9.42 & 0.640 & 0.998 & 0.953 & 0.129 \\
\hline Lesotho & 89834 & 85178 & 46185 & 4.74 & 3.40 & 3.05 & 1.68 & 1 & 1.37 & 11.34 & 0.661 & 1.000 & 0.980 & 0.190 \\
\hline Zambia & 89626 & 78337 & 46010 & 5.13 & 5.40 & 4.84 & 0.29 & 1 & 0.81 & 11.14 & 0.571 & 0.848 & 0.961 & 0.135 \\
\hline Malawi & 92156 & 84640 & 55900 & 5.81 & 5.84 & 5.38 & 0.43 & 1 & 0.94 & 11.32 & 0.675 & 0.865 & 0.961 & 0.090 \\
\hline Mozambique & 89996 & 82949 & 55164 & 5.81 & 5.30 & 4.77 & 1.04 & 1 & 0.66 & 29.96 & 0.797 & 0.752 & 0.978 & 0.226 \\
\hline Central African R. & 88460 & 77387 & 52196 & 5.87 & 4.73 & 4.18 & 1.68 & 1 & 0.57 & 8.13 & & & & \\
\hline Angola & 84615 & 69916 & 53036 & 6.52 & 6.56 & 5.55 & 0.97 & 1 & & 14.20 & 0.585 & 0.779 & 0.980 & 0.070 \\
\hline Sierra Leone & 83491 & 66419 & 51071 & 6.58 & 6.48 & 5.41 & 1.17 & 1 & & 12.63 & & & & \\
\hline Kenya & 92167 & 86349 & 64952 & 6.62 & 4.98 & 4.59 & 2.03 & 1 & 0.97 & 5.66 & 0.649 & 0.934 & 0.968 & 0.053 \\
\hline Niger & 84993 & 67741 & 53223 & 6.76 & 7.67 & 6.52 & 0.24 & 1 & 0.67 & 7.35 & & & & \\
\hline Tanzania & 92429 & 83740 & 64580 & 6.79 & 5.20 & 4.81 & 1.98 & 1 & 1.01 & 21.68 & 0.780 & 0.859 & 0.969 & 0.180 \\
\hline Rwanda & 88177 & 75770 & 60670 & 6.96 & 5.80 & 5.11 & 1.84 & 1 & 0.93 & 36.16 & & & & \\
\hline Equatorial Guinea & 87686 & 76066 & 61565 & 7.02 & 5.89 & 5.16 & 1.86 & 1 & 0.85 & 13.20 & & & & \\
\hline Uganda & 92063 & 83260 & 66927 & 7.07 & 7.10 & 6.54 & 0.53 & 1 & 0.86 & 23.52 & 0.676 & 0.874 & 0.976 & 0.207 \\
\hline Guinea-Bissau & 87602 & 76769 & 62687 & 7.08 & 7.08 & 6.20 & 0.88 & 1 & 0.56 & 12.00 & & & & \\
\hline Burundi & 88588 & 77296 & 63517 & 7.15 & 6.80 & 6.02 & 1.13 & 1 & 0.77 & 21.38 & & & & \\
\hline Nigeria & 89918 & 76981 & 63028 & 7.15 & 5.70 & 5.13 & 2.03 & 1 & 0.83 & 6.13 & 0.621 & 0.808 & 0.969 & 0.052 \\
\hline Congo, Democratic R. & 92057 & 87101 & 71300 & 7.20 & 6.70 & 6.17 & 1.03 & 1 & 0.67 & 8.10 & & & & \\
\hline Chad & 87580 & 75209 & 62506 & 7.21 & 6.30 & 5.52 & 1.69 & 1 & 0.46 & 7.50 & 0.652 & 0.470 & 0.976 & 0.054 \\
\hline Mali & 87968 & 74634 & 62128 & 7.23 & 6.72 & 5.91 & 1.32 & 1 & 0.65 & 8.84 & 0.695 & 0.652 & 0.969 & 0.091 \\
\hline Namibia & 95390 & 93106 & 60821 & 5.80 & 3.66 & 3.49 & 2.31 & 0 & 1.12 & 23.98 & 0.672 & 0.993 & 0.968 & 0.172 \\
\hline South Africa & 94923 & 91305 & 63410 & 6.16 & 2.78 & 2.64 & 3.52 & 0 & 1.03 & 30.76 & 0.586 & 0.991 & 0.975 & 0.326 \\
\hline Cte d'Ivoire & 88161 & 80007 & 60586 & 6.58 & 4.70 & 4.14 & 2.44 & 0 & 0.64 & 7.90 & & & & \\
\hline Afghanistan & 83498 & 68111 & 55158 & 6.93 & & & 6.93 & 0 & 0.39 & 27.15 & & & & \\
\hline Cameroon & 91273 & 82767 & 65486 & 6.94 & 5.00 & 4.56 & 2.38 & 0 & 0.87 & 8.98 & 0.511 & 0.826 & 0.969 & 0.061 \\
\hline Gabon & 94084 & 90272 & 72948 & 7.15 & 3.73 & 3.51 & 3.64 & 0 & 1.04 & 9.04 & & & & \\
\hline Burkina Faso & 90358 & 76858 & 64916 & 7.39 & 5.90 & 5.33 & 2.06 & 0 & 0.73 & 9.54 & 0.631 & 0.680 & 0.970 & 0.084 \\
\hline Benin & 91090 & 81776 & 70462 & 7.55 & 5.60 & 5.10 & 2.45 & 0 & 0.59 & 7.24 & 0.543 & 0.658 & 0.975 & 0.086 \\
\hline Haiti & 91681 & 85712 & 73746 & 7.56 & 3.75 & 3.44 & 4.12 & 0 & & 3.60 & & & & \\
\hline Ethiopia & 89107 & 81621 & 70824 & 7.56 & 5.32 & 4.74 & 2.82 & 0 & & 11.78 & 0.585 & 0.740 & 0.969 & 0.102 \\
\hline Djibouti & 91200 & 84729 & 73610 & 7.62 & 4.74 & 4.32 & 3.30 & 0 & 0.72 & 6.56 & & & & \\
\hline Togo & 92170 & 84671 & 73395 & 7.62 & 5.03 & 4.64 & 2.99 & 0 & 0.67 & 6.40 & & & & \\
\hline Guinea & 90214 & 82506 & 72676 & 7.70 & 5.60 & 5.05 & 2.65 & 0 & 0.60 & 14.66 & & & & \\
\hline Gambia, The & 90344 & 84506 & 75416 & 7.81 & 4.40 & 3.98 & 3.83 & 0 & & 9.30 & 0.687 & 0.808 & 0.980 & 0.094 \\
\hline Ghana & 93205 & 86636 & 76715 & 7.81 & 4.06 & 3.78 & 4.03 & 0 & 0.94 & 9.78 & 0.781 & 0.871 & 0.967 & 0.071 \\
\hline Cambodia & 90215 & 84435 & 75424 & 7.81 & 3.89 & 3.51 & 4.30 & 0 & 0.88 & 8.76 & 0.664 & 0.845 & 0.980 & 0.053 \\
\hline Senegal & 92292 & 84196 & 76237 & 7.97 & 4.90 & 4.52 & 3.44 & 0 & 0.81 & 16.24 & & & & \\
\hline Eritrea & 95031 & 91232 & 82345 & 8.00 & 5.24 & 4.98 & 3.02 & 0 & 0.75 & 20.40 & & & & \\
\hline Sudan & 93792 & 89544 & 81516 & 8.04 & 4.15 & 3.89 & 4.15 & 0 & 0.87 & 11.14 & & & & \\
\hline
\end{tabular}




\begin{tabular}{|c|c|c|c|c|c|c|c|c|c|c|c|c|c|c|}
\hline \multirow[t]{2}{*}{ Country } & L1 & $\begin{array}{r}\text { L20 } \\
\text { females }\end{array}$ & $\begin{array}{r}\text { L40 } \\
\text { females }\end{array}$ & $\begin{array}{r}\text { Max } \\
\text { net } \\
\text { fertility }\end{array}$ & $\begin{array}{r}\text { Birth } \\
\text { per } \\
\text { woman }\end{array}$ & $\begin{array}{r}\text { Net birth } \\
\text { per } \\
\text { woman }\end{array}$ & $\begin{array}{r}\text { Fertility } \\
\text { margin }\end{array}$ & $\begin{array}{r}\text { Malthus } \\
\text { regime }\end{array}$ & $\begin{array}{c}\text { girls/ boys } \\
\text { Primary } \\
\text { Complet. }\end{array}$ & $\begin{array}{r}\text { parliamentary } \\
\text { seats occup. } \\
\text { by women } \%\end{array}$ & $\begin{array}{l}\text { Economic } \\
\text { Particip. } \\
\& \text { Opport. }\end{array}$ & $\begin{array}{r}\text { Educ. } \\
\text { Attain- } \\
\text {-ment }\end{array}$ & $\begin{array}{r}\text { Health } \\
\text { and } \\
\text { Survival }\end{array}$ & $\begin{array}{l}\text { Political } \\
\text { Empow- } \\
\text {-erment }\end{array}$ \\
\hline & World & \multicolumn{2}{|c|}{ Health Organization } & Eq.(15) & WDI & \multicolumn{3}{|c|}{ Our computations } & WDI & U.N. & \multicolumn{4}{|c|}{ World Economic Forum } \\
\hline Lao & 93792 & 89862 & 82330 & 8.09 & 3.59 & 3.37 & 4.73 & 0 & 0.88 & 20.64 & & & & \\
\hline Guyana & 95300 & 92118 & 84164 & 8.11 & 2.18 & 2.08 & 6.03 & 0 & 0.95 & 23.56 & & & & \\
\hline Mauritania & 92213 & 86119 & 79397 & 8.11 & 5.59 & 5.15 & 2.95 & 0 & 0.90 & 6.50 & 0.505 & 0.832 & 0.980 & 0.092 \\
\hline Nepal & 94376 & 89729 & 82628 & 8.15 & 3.46 & 3.27 & 4.88 & 0 & 0.83 & 8.73 & 0.457 & 0.734 & 0.955 & 0.085 \\
\hline Myanmar & 92591 & 88851 & 82378 & 8.16 & 2.23 & 2.06 & 6.10 & 0 & 1.00 & & & & & \\
\hline Madagascar & 92598 & 86321 & 80399 & 8.20 & 5.04 & 4.67 & 3.53 & 0 & 1.02 & 5.98 & 0.609 & 0.958 & 0.980 & 0.038 \\
\hline São Tomé and Príncipe & 92502 & 86290 & 80606 & 8.22 & 3.76 & 3.48 & 4.75 & 0 & 1.09 & 7.86 & & & & \\
\hline Bangladesh & 94601 & 90884 & 84642 & 8.25 & 2.98 & 2.82 & 5.43 & 0 & 1.06 & 10.36 & 0.437 & 0.871 & 0.950 & 0.267 \\
\hline Yemen, R. & 92402 & 88042 & 82927 & 8.29 & 5.87 & 5.42 & 2.87 & 0 & 0.53 & 0.46 & 0.251 & 0.565 & 0.980 & 0.008 \\
\hline Pakistan & 92048 & 87990 & 83190 & 8.31 & 4.12 & 3.79 & 4.52 & 0 & & 13.66 & 0.372 & 0.734 & 0.950 & 0.148 \\
\hline India & 94399 & 90108 & 84886 & 8.34 & 2.84 & 2.68 & 5.66 & 0 & 0.86 & 8.06 & 0.398 & 0.819 & 0.931 & 0.227 \\
\hline Comoros & 94696 & 92041 & 88115 & 8.48 & 3.76 & 3.56 & 4.92 & 0 & 0.91 & 2.00 & & & & \\
\hline Bolivia & 94801 & 92162 & 88242 & 8.48 & 3.65 & 3.46 & 5.02 & 0 & 0.95 & 15.18 & 0.607 & 0.968 & 0.967 & 0.087 \\
\hline Thailand & 98202 & 97037 & 92539 & 8.53 & 1.89 & 1.86 & 6.67 & 0 & 0.98 & 7.50 & 0.724 & 0.973 & 0.980 & 0.050 \\
\hline Indonesia & 97194 & 95335 & 91234 & 8.53 & 2.27 & 2.21 & 6.33 & 0 & 1.01 & 11.33 & 0.599 & 0.949 & 0.972 & 0.101 \\
\hline Kazakhstan & 97331 & 96583 & 92423 & 8.54 & 1.75 & 1.70 & 6.83 & 0 & 0.99 & 10.60 & 0.737 & 0.989 & 0.979 & 0.089 \\
\hline Turkmenistan & 91891 & 90447 & 87958 & 8.55 & 2.60 & 2.39 & 6.16 & 0 & & 18.80 & & & & \\
\hline Honduras & 96914 & 95079 & 91232 & 8.55 & 3.47 & 3.36 & 5.19 & 0 & & 13.68 & 0.549 & 1.000 & 0.980 & 0.136 \\
\hline Kyrgyz Republic & 94196 & 93223 & 90209 & 8.56 & 2.41 & 2.27 & 6.29 & 0 & 0.99 & 4.00 & 0.653 & 0.994 & 0.980 & 0.035 \\
\hline Guatemala & 96793 & 94567 & 90881 & 8.56 & 4.33 & 4.19 & 4.37 & 0 & 0.86 & 9.04 & 0.471 & 0.897 & 0.980 & 0.110 \\
\hline Tajikistan & 94100 & 92630 & 89982 & 8.59 & 3.53 & 3.32 & 5.27 & 0 & 0.94 & 10.90 & 0.710 & 0.869 & 0.979 & 0.074 \\
\hline Russia & 98906 & 98159 & 94385 & 8.61 & 1.29 & 1.28 & 7.34 & 0 & & 10.56 & 0.735 & 0.999 & 0.979 & 0.034 \\
\hline Uzbekistan & 94276 & 93874 & 91390 & 8.61 & 2.22 & 2.09 & 6.52 & 0 & 1.00 & 10.90 & 0.754 & 0.963 & 0.977 & 0.075 \\
\hline Philippines & 97505 & 96328 & 93058 & 8.62 & 3.20 & 3.12 & 5.50 & 0 & 1.08 & 13.34 & 0.789 & 1.000 & 0.980 & 0.283 \\
\hline Dominican R. & 97402 & 96553 & 93323 & 8.62 & 2.95 & 2.87 & 5.75 & 0 & 1.10 & 16.94 & 0.585 & 1.000 & 0.980 & 0.117 \\
\hline Mongolia & 96083 & 95296 & 92619 & 8.64 & 2.33 & 2.24 & 6.40 & 0 & 1.05 & 6.12 & 0.668 & 0.999 & 0.980 & 0.046 \\
\hline Suriname & 97000 & 95166 & 92328 & 8.65 & 2.51 & 2.43 & 6.21 & 0 & 1.16 & 18.30 & 0.617 & 0.989 & 0.973 & 0.139 \\
\hline Belize & 98500 & 98005 & 94742 & 8.65 & 2.97 & 2.93 & 5.72 & 0 & & 5.34 & 0.552 & 1.000 & 0.980 & 0.039 \\
\hline Azerbaijan & 92582 & 90991 & 89424 & 8.65 & 2.33 & 2.16 & 6.50 & 0 & 0.99 & 9.46 & 0.732 & 0.971 & 0.926 & 0.083 \\
\hline Trinidad and Tobago & 98300 & 97784 & 94731 & 8.66 & 1.61 & 1.58 & 7.08 & 0 & 1.00 & 17.48 & 0.639 & 0.996 & 0.980 & 0.130 \\
\hline Fiji & 98400 & 97458 & 94433 & 8.67 & 2.79 & 2.75 & 5.92 & 0 & 1.02 & 8.08 & & & & \\
\hline Ukraine & 98700 & 98061 & 95054 & 8.68 & 1.20 & 1.18 & 7.49 & 0 & & 6.62 & 0.708 & 0.984 & 0.973 & 0.050 \\
\hline Nicaragua & 97028 & 95875 & 93394 & 8.68 & 3.08 & 2.99 & 5.69 & 0 & 1.11 & 17.34 & 0.434 & 0.991 & 0.976 & 0.181 \\
\hline Peru & 97702 & 96653 & 94017 & 8.69 & 2.86 & 2.79 & 5.89 & 0 & 0.98 & 19.44 & 0.537 & 0.976 & 0.971 & 0.165 \\
\hline Lebanon & 97287 & 96583 & 94053 & 8.69 & 2.25 & 2.19 & 6.50 & 0 & 1.04 & 3.14 & & & & \\
\hline Ecuador & 97800 & 96728 & 94083 & 8.69 & 2.67 & 2.61 & 6.08 & 0 & 1.01 & 15.60 & 0.634 & 0.994 & 0.980 & 0.145 \\
\hline Algeria & 96602 & 95350 & 93042 & 8.69 & 2.44 & 2.36 & 6.33 & 0 & 1.00 & 5.64 & 0.464 & 0.942 & 0.971 & 0.049 \\
\hline Jamaica & 98319 & 97489 & 94834 & 8.70 & 2.38 & 2.34 & 6.36 & 0 & 1.05 & 12.14 & 0.701 & 1.000 & 0.971 & 0.098 \\
\hline El Salvador & 97694 & 96839 & 94377 & 8.70 & 2.76 & 2.70 & 6.01 & 0 & 1.00 & 14.54 & 0.576 & 0.988 & 0.980 & 0.197 \\
\hline Egypt & 97198 & 95832 & 93586 & 8.71 & 3.10 & 3.01 & 5.70 & 0 & 0.95 & 2.00 & 0.421 & 0.909 & 0.972 & 0.022 \\
\hline Iran & 96884 & 95817 & 93789 & 8.72 & 2.07 & 2.01 & 6.72 & 0 & & 3.82 & 0.395 & 0.958 & 0.978 & 0.031 \\
\hline
\end{tabular}




\begin{tabular}{|c|c|c|c|c|c|c|c|c|c|c|c|c|c|c|}
\hline \multirow[t]{2}{*}{ Country } & L1 & $\begin{array}{r}\text { L20 } \\
\text { females }\end{array}$ & $\begin{array}{r}\text { L40 } \\
\text { females }\end{array}$ & $\begin{array}{r}\text { Max } \\
\text { net } \\
\text { fertility }\end{array}$ & $\begin{array}{r}\text { Birth } \\
\text { per } \\
\text { woman }\end{array}$ & $\begin{array}{r}\text { Net birth } \\
\text { per } \\
\text { woman }\end{array}$ & $\begin{array}{r}\text { Fertility } \\
\text { margin }\end{array}$ & $\begin{array}{r}\text { Malthus } \\
\text { regime }\end{array}$ & $\begin{array}{c}\text { girls/ boys } \\
\text { Primary } \\
\text { Complet. }\end{array}$ & $\begin{array}{r}\text { parliamentary } \\
\text { seats occup. } \\
\text { by women } \%\end{array}$ & $\begin{array}{l}\text { Economic } \\
\text { Particip. } \\
\text { \& Opport. }\end{array}$ & $\begin{array}{r}\text { Educ. } \\
\text { Attain- } \\
\text {-ment }\end{array}$ & $\begin{array}{r}\text { Health } \\
\text { and } \\
\text { Survival }\end{array}$ & $\begin{array}{l}\text { Political } \\
\text { Empow- } \\
\text {-erment }\end{array}$ \\
\hline & \multicolumn{3}{|c|}{ World Health Organization } & Eq.(15) & WDI & \multicolumn{3}{|c|}{ Our computations } & WDI & U.N. & \multicolumn{4}{|c|}{ World Economic Forum } \\
\hline Brazil & 97244 & 96507 & 94398 & 8.72 & 2.28 & 2.22 & 6.51 & 0 & 1.01 & 7.92 & 0.645 & 0.969 & 0.980 & 0.062 \\
\hline Jordan & 97798 & 96776 & 94622 & 8.73 & 3.29 & 3.22 & 5.51 & 0 & 1.00 & 3.70 & 0.483 & 0.979 & 0.971 & 0.048 \\
\hline Saudi Arabia & 97879 & 96905 & 94755 & 8.73 & 3.83 & 3.75 & 4.99 & 0 & & 0.00 & 0.321 & 0.961 & 0.976 & 0.000 \\
\hline Turkey & 97398 & 96512 & 94504 & 8.74 & 2.19 & 2.13 & 6.60 & 0 & 0.90 & 3.68 & 0.431 & 0.854 & 0.971 & 0.052 \\
\hline Morocco & 96393 & 95801 & 94064 & 8.74 & 2.40 & 2.31 & 6.42 & 0 & & 6.96 & 0.401 & 0.845 & 0.972 & 0.053 \\
\hline Belarus & 99328 & 98832 & 96483 & 8.75 & 1.24 & 1.23 & 7.52 & 0 & & 29.03 & 0.728 & 0.983 & 0.979 & 0.155 \\
\hline Vietnam & 98403 & 97546 & 95457 & 8.75 & 1.78 & 1.75 & 7.00 & 0 & 0.94 & 25.06 & 0.745 & 0.892 & 0.970 & 0.148 \\
\hline Venezuela & 98200 & 97491 & 95508 & 8.76 & 2.65 & 2.60 & 6.16 & 0 & 1.06 & 13.20 & 0.631 & 0.999 & 0.980 & 0.110 \\
\hline Syrian Arab R. & 98602 & 98136 & 96062 & 8.76 & 3.24 & 3.19 & 5.57 & 0 & & 11.20 & 0.524 & 0.927 & 0.976 & 0.059 \\
\hline Tunisia & 97999 & 97309 & 95414 & 8.76 & 2.04 & 2.00 & 6.76 & 0 & & 16.56 & 0.474 & 0.959 & 0.970 & 0.110 \\
\hline Albania & 98400 & 97217 & 95277 & 8.77 & 1.78 & 1.75 & 7.02 & 0 & 1.00 & 6.22 & 0.689 & 0.992 & 0.955 & 0.038 \\
\hline China & 97688 & 96298 & 94623 & 8.77 & 1.81 & 1.77 & 7.01 & 0 & & 20.66 & 0.648 & 0.957 & 0.941 & 0.111 \\
\hline Panama & 98100 & 97190 & 95412 & 8.77 & 2.62 & 2.57 & 6.20 & 0 & & 14.68 & 0.655 & 0.994 & 0.980 & 0.153 \\
\hline Georgia & 95921 & 95970 & 94758 & 8.77 & 1.39 & 1.33 & 7.44 & 0 & & 8.08 & 0.630 & 0.998 & 0.933 & 0.104 \\
\hline Moldova & 98601 & 98158 & 96240 & 8.77 & 1.27 & 1.25 & 7.52 & 0 & 0.99 & 14.16 & 0.778 & 0.994 & 0.979 & 0.117 \\
\hline Colombia & 98296 & 97573 & 95742 & 8.77 & 2.40 & 2.36 & 6.42 & 0 & 1.05 & 10.75 & 0.691 & 1.000 & 0.980 & 0.166 \\
\hline Sri Lanka & 98802 & 98289 & 96347 & 8.78 & 1.91 & 1.89 & 6.89 & 0 & & 4.98 & 0.557 & 0.990 & 0.980 & 0.365 \\
\hline Paraguay & 98000 & 97375 & 95679 & 8.78 & 3.67 & 3.60 & 5.18 & 0 & 0.59 & 7.20 & 0.594 & 0.945 & 0.980 & 0.144 \\
\hline Maldives & 96698 & 95481 & 94306 & 8.80 & 4.00 & 3.87 & 4.93 & 0 & & 8.40 & 0.514 & 1.000 & 0.951 & 0.075 \\
\hline Mexico & 97794 & 97122 & 95678 & 8.80 & 2.11 & 2.06 & 6.73 & 0 & 1.01 & 19.25 & 0.489 & 0.992 & 0.980 & 0.116 \\
\hline Armenia & 97399 & 97013 & 95681 & 8.80 & 1.37 & 1.33 & 7.47 & 0 & 1.01 & 5.10 & 0.721 & 0.999 & 0.923 & 0.017 \\
\hline Latvia & 99201 & 98685 & 96917 & 8.80 & 1.31 & 1.30 & 7.50 & 0 & & 18.60 & 0.734 & 0.986 & 0.980 & 0.233 \\
\hline Lithuania & 99313 & 98935 & 97193 & 8.81 & 1.27 & 1.26 & 7.55 & 0 & & 18.60 & 0.761 & 0.998 & 0.979 & 0.155 \\
\hline Mauritius & 98694 & 98274 & 96760 & 8.81 & 1.98 & 1.95 & 6.86 & 0 & & 10.22 & 0.547 & 0.983 & 0.980 & 0.085 \\
\hline Malaysia & 99000 & 98399 & 96860 & 8.82 & 2.74 & 2.71 & 6.11 & 0 & 1.00 & 8.62 & 0.567 & 0.985 & 0.969 & 0.056 \\
\hline Argentina & 98603 & 98118 & 96714 & 8.82 & 2.29 & 2.26 & 6.56 & 0 & & 30.80 & 0.613 & 0.996 & 0.980 & 0.204 \\
\hline Bosnia and Herzegovina & 98700 & 98225 & 96813 & 8.82 & 1.19 & 1.17 & 7.65 & 0 & & 12.93 & & & & \\
\hline Romania & 98383 & 97898 & 96589 & 8.83 & 1.32 & 1.30 & 7.53 & 0 & 0.99 & 8.84 & 0.697 & 0.993 & 0.979 & 0.074 \\
\hline Bulgaria & 98809 & 98308 & 96891 & 8.83 & 1.31 & 1.29 & 7.53 & 0 & & 18.82 & 0.699 & 0.989 & 0.979 & 0.167 \\
\hline Oman & 98999 & 98424 & 96959 & 8.83 & 3.44 & 3.41 & 5.42 & 0 & 0.98 & 2.20 & 0.384 & 0.971 & 0.971 & 0.035 \\
\hline Uruguay & 98699 & 98275 & 96888 & 8.83 & 2.00 & 1.97 & 6.85 & 0 & & 9.03 & 0.634 & 0.991 & 0.980 & 0.039 \\
\hline Estonia & 99448 & 98898 & 97443 & 8.84 & 1.50 & 1.49 & 7.35 & 0 & & 18.70 & 0.694 & 0.999 & 0.979 & 0.131 \\
\hline United States & 99341 & 98971 & 97590 & 8.84 & 2.05 & 2.04 & 6.81 & 0 & & 13.84 & 0.738 & 0.982 & 0.979 & 0.102 \\
\hline Costa Rica & 98900 & 98530 & 97339 & 8.85 & 2.00 & 1.98 & 6.87 & 0 & & 29.12 & 0.554 & 0.995 & 0.980 & 0.277 \\
\hline Cuba & 99476 & 99070 & 97838 & 8.86 & 1.50 & 1.49 & 7.37 & 0 & & 31.80 & 0.681 & 0.990 & 0.974 & 0.222 \\
\hline Hungary & 99366 & 99088 & 97902 & 8.86 & 1.32 & 1.31 & 7.55 & 0 & 1.00 & 9.88 & 0.653 & 0.991 & 0.979 & 0.069 \\
\hline Macedonia, FYR & 98499 & 98274 & 97391 & 8.87 & 1.60 & 1.58 & 7.29 & 0 & & 14.25 & 0.665 & 0.985 & 0.963 & 0.173 \\
\hline Bahrain & 99099 & 98582 & 97574 & 8.87 & 2.34 & 2.32 & 6.55 & 0 & & 1.50 & 0.390 & 0.989 & 0.961 & 0.031 \\
\hline Chile & 99200 & 98806 & 97807 & 8.87 & 1.97 & 1.95 & 6.92 & 0 & & 12.40 & 0.517 & 0.980 & 0.980 & 0.116 \\
\hline Korea & 99504 & 99195 & 98155 & 8.88 & 1.08 & 1.07 & 7.80 & 0 & 1.01 & 9.08 & 0.580 & 0.949 & 0.967 & 0.067 \\
\hline Portugal & 99635 & 99239 & 98179 & 8.88 & 1.40 & 1.39 & 7.48 & 0 & 1.06 & 16.66 & 0.684 & 0.989 & 0.973 & 0.138 \\
\hline
\end{tabular}




\begin{tabular}{|c|c|c|c|c|c|c|c|c|c|c|c|c|c|c|}
\hline \multirow[t]{2}{*}{ Country } & L1 & $\begin{array}{r}\text { L20 } \\
\text { females }\end{array}$ & $\begin{array}{r}\text { L40 } \\
\text { females }\end{array}$ & $\begin{array}{r}\text { Max } \\
\text { net } \\
\text { fertility }\end{array}$ & $\begin{array}{r}\text { Birth } \\
\text { per } \\
\text { woman }\end{array}$ & $\begin{array}{r}\text { Net birth } \\
\text { per } \\
\text { woman }\end{array}$ & $\begin{array}{r}\text { Fertility } \\
\text { gap }\end{array}$ & $\begin{array}{r}\text { Malthus } \\
\text { regime }\end{array}$ & $\begin{array}{c}\text { girls/ boys } \\
\text { Primary } \\
\text { Complet. }\end{array}$ & $\begin{array}{r}\text { parliamentary } \\
\text { seats occup. } \\
\text { by women } \%\end{array}$ & $\begin{array}{c}\text { Economic } \\
\text { Particip. } \\
\text { \& Opport. }\end{array}$ & $\begin{array}{r}\text { Educ. } \\
\text { Attain- } \\
\text {-ment }\end{array}$ & $\begin{array}{r}\text { Health } \\
\text { and } \\
\text { Survival }\end{array}$ & $\begin{array}{l}\text { Political } \\
\text { Empow- } \\
\text {-erment }\end{array}$ \\
\hline & \multicolumn{3}{|c|}{ World Health Organization } & Eq.(15) & WDI & \multicolumn{3}{|c|}{ Our computations } & WDI & U.N. & \multicolumn{4}{|c|}{ World Economic Forum } \\
\hline Slovak Republic & 99277 & 98989 & 98033 & 8.88 & 1.25 & 1.24 & 7.64 & 0 & 1.00 & 16.60 & 0.667 & 0.995 & 0.980 & 0.077 \\
\hline United Arab Emirates & 99201 & 98925 & 97993 & 8.88 & 2.43 & 2.41 & 6.47 & 0 & & 5.75 & 0.421 & 0.987 & 0.961 & 0.105 \\
\hline New Zealand & 99466 & 99088 & 98093 & 8.88 & 2.00 & 1.99 & 6.89 & 0 & & 28.44 & 0.755 & 0.999 & 0.974 & 0.331 \\
\hline Poland & 99355 & 99047 & 98120 & 8.88 & 1.24 & 1.23 & 7.65 & 0 & & 17.28 & 0.617 & 1.000 & 0.979 & 0.107 \\
\hline United Kingdom & 99502 & 99246 & 98291 & 8.88 & 1.80 & 1.79 & 7.09 & 0 & & 17.14 & 0.695 & 1.000 & 0.974 & 0.307 \\
\hline Norway & 99686 & 99332 & 98399 & 8.89 & 1.84 & 1.83 & 7.06 & 0 & 1.00 & 37.38 & 0.751 & 1.000 & 0.979 & 0.494 \\
\hline Belgium & 99628 & 99384 & 98471 & 8.89 & 1.72 & 1.71 & 7.18 & 0 & & 27.94 & 0.668 & 1.000 & 0.979 & 0.232 \\
\hline France & 99628 & 99398 & 98490 & 8.89 & 1.92 & 1.91 & 6.98 & 0 & 0.99 & 10.64 & 0.646 & 1.000 & 0.980 & 0.104 \\
\hline Finland & 99690 & 99394 & 98502 & 8.89 & 1.80 & 1.79 & 7.10 & 0 & 1.00 & 37.70 & 0.723 & 0.999 & 0.980 & 0.517 \\
\hline Croatia & 99436 & 99128 & 98302 & 8.89 & 1.42 & 1.41 & 7.48 & 0 & & 15.14 & 0.678 & 0.989 & 0.979 & 0.238 \\
\hline Canada & 99505 & 99256 & 98415 & 8.89 & 1.51 & 1.50 & 7.39 & 0 & & 20.36 & 0.743 & 0.999 & 0.979 & 0.159 \\
\hline Australia & 99491 & 99242 & 98413 & 8.90 & 1.77 & 1.76 & 7.13 & 0 & & 21.34 & 0.744 & 1.000 & 0.974 & 0.163 \\
\hline Czech Republic & 99654 & 99365 & 98511 & 8.90 & 1.28 & 1.28 & 7.62 & 0 & 1.00 & 14.70 & 0.630 & 0.991 & 0.979 & 0.088 \\
\hline Iceland & 99786 & 99536 & 98659 & 8.90 & 2.05 & 2.05 & 6.85 & 0 & 0.98 & 31.26 & 0.721 & 0.987 & 0.970 & 0.456 \\
\hline Kuwait & 99034 & 98528 & 97846 & 8.90 & 2.39 & 2.37 & 6.53 & 0 & & 0.90 & 0.604 & 0.989 & 0.961 & 0.010 \\
\hline Denmark & 99590 & 99349 & 98529 & 8.90 & 1.80 & 1.79 & 7.11 & 0 & 1.00 & 36.38 & 0.734 & 1.000 & 0.970 & 0.305 \\
\hline Slovenia & 99666 & 99394 & 98556 & 8.90 & 1.23 & 1.23 & 7.67 & 0 & & 11.64 & 0.705 & 0.999 & 0.973 & 0.060 \\
\hline Greece & 99617 & 99292 & 98468 & 8.90 & 1.28 & 1.28 & 7.62 & 0 & 0.99 & 10.40 & 0.630 & 0.989 & 0.979 & 0.061 \\
\hline Netherlands & 99564 & 99355 & 98544 & 8.90 & 1.73 & 1.72 & 7.18 & 0 & 0.99 & 35.54 & 0.667 & 0.993 & 0.974 & 0.319 \\
\hline Ireland & 99602 & 99252 & 98433 & 8.90 & 1.88 & 1.87 & 7.03 & 0 & 1.01 & 12.86 & 0.667 & 1.000 & 0.973 & 0.343 \\
\hline Qatar & 98976 & 98607 & 97975 & 8.90 & 2.89 & 2.86 & 6.04 & 0 & & 0.00 & 0.456 & 0.993 & 0.947 & 0.021 \\
\hline Japan & 99722 & 99483 & 98661 & 8.90 & 1.26 & 1.26 & 7.64 & 0 & & 6.00 & 0.549 & 0.986 & 0.979 & 0.067 \\
\hline Austria & 99587 & 99293 & 98521 & 8.90 & 1.41 & 1.40 & 7.50 & 0 & 0.99 & 29.98 & 0.582 & 0.980 & 0.980 & 0.282 \\
\hline Luxembourg & 99580 & 99391 & 98632 & 8.90 & 1.70 & 1.69 & 7.21 & 0 & 1.05 & 20.66 & 0.606 & 1.000 & 0.973 & 0.135 \\
\hline Switzerland & 99578 & 99369 & 98614 & 8.90 & 1.42 & 1.41 & 7.49 & 0 & 1.02 & 22.80 & 0.676 & 0.957 & 0.978 & 0.158 \\
\hline Cyprus & 99647 & 99474 & 98709 & 8.90 & 1.42 & 1.41 & 7.49 & 0 & & 9.66 & 0.602 & 0.989 & 0.966 & 0.052 \\
\hline Malta & 99472 & 99288 & 98569 & 8.90 & 1.37 & 1.36 & 7.54 & 0 & & 7.64 & 0.549 & 0.998 & 0.974 & 0.126 \\
\hline Spain & 99622 & 99376 & 98627 & 8.91 & 1.33 & 1.32 & 7.58 & 0 & 0.99 & 29.20 & 0.589 & 0.994 & 0.973 & 0.421 \\
\hline Israel & 99568 & 99303 & 98581 & 8.91 & 2.82 & 2.81 & 6.10 & 0 & & 12.84 & 0.671 & 0.995 & 0.970 & 0.150 \\
\hline Germany & 99614 & 99387 & 98664 & 8.91 & 1.36 & 1.35 & 7.55 & 0 & 1.00 & 30.56 & 0.700 & 0.995 & 0.978 & 0.374 \\
\hline Italy & 99630 & 99414 & 98726 & 8.91 & 1.32 & 1.32 & 7.60 & 0 & 1.00 & 14.46 & 0.543 & 0.997 & 0.972 & 0.087 \\
\hline Singapore & 99755 & 99538 & 98822 & 8.91 & 1.24 & 1.24 & 7.67 & 0 & & 14.04 & 0.655 & 0.931 & 0.958 & 0.101 \\
\hline Sweden & 99696 & 99480 & 98829 & 8.92 & 1.77 & 1.76 & 7.15 & 0 & & 44.06 & 0.761 & 0.999 & 0.974 & 0.525 \\
\hline Iraq & 100000 & 100000 & 100000 & 8.98 & 5.37 & 5.37 & 3.61 & 0 & 0.76 & 17.13 & & & & \\
\hline Average & 95861 & 92832 & 86414 & 8.22 & 3.03 & 2.85 & 5.38 & 0.14 & 0.92 & 13.92 & 0.616 & 0.943 & 0.972 & 0.138 \\
\hline Std & 4066 & 7974 & 15444 & 1.02 & 1.64 & 1.42 & 2.20 & 0.35 & 0.16 & 8.81 & 0.110 & 0.096 & 0.011 & 0.108 \\
\hline Corr with fertility margin: & & & & & & & & & & & & & & \\
\hline -Whole sample & & & & & & & 1.00 & & 0.490 & 0.174 & 0.128 & 0.658 & 0.095 & 0.163 \\
\hline -Malthus regime & & & & & & & 1.00 & & 0.136 & 0.028 & 0.174 & 0.048 & 0.010 & -0.250 \\
\hline - Interior regime & & & & & & & 1.00 & & 0.518 & 0.275 & 0.367 & 0.685 & 0.039 & 0.202 \\
\hline
\end{tabular}




\section{References}

[1] Albanesi, Stefania and Claudia Olivetti (2007), "Gender Roles and Technological Progress", CEPR Discussion Papers n6352, June 2007.

[2] Bar, Michael, and Oksana Leukhina (2008), "Demographic Transition and Industrial Revolution: A Macroeconomic Investigation", Unpublished research paper, January 2008.

[3] Barro Robert J., and Gary S. Becker (1988), "A Reformulation of the Economic Theory of Fertility", Quaterly Journal of Economics, February, 103(1), 1-25.

[4] Barro Robert J., and Gary S. Becker (1989), "Fertility Choice in a Model Economic Growth", Econometrica, March, 57(2), 481-501.

[5] Becker, Gary S. (1991), A Treatise on the Family, Enlarged ed.. Cambridge MA: Harvard University Press, 1991.

[6] Becker Gary S., Kevin M. Murphy, and Robert Tamura (1990), "Human Capital, Fertility, and Economic Growth", Journal of Political Economy, October, 98(5), S12-S37.

[7] Ben-Porath, Yoram. (1967), "The production of human capital and the life-cycle of earnings", Journal of Political Economy 75 (4): 352-365.

[8] Boucekkine Raouf, David de la Croix and Omar Licandro (2002), "Vintage human capital, demographic trends and growth", Journal of Economic Theory, 104, 340375.

[9] Browning Martin, and Pierre-André Chiappori (1998), "Efficient Intra-Household Allocations: A General Characterization and Empirical Tests", Econometrica, November, 66(6), 1241-1278.

[10] Chiappori Pierre-André. (1988), "Rational Household Labor Supply", Econometrica, 56: 63-90.

[11] Chiappori Pierre-André. (1992), "Collective Labor Supply and Welfare", Journal of Political Economy, 100(3): 437-67. 
[12] Chiappori Pierre-André and Olivier Donni (2006). "Les modèles non-unitaires de comportement du ménage: un survol de la littérature". Actualité Économique: Revue d'Analyse Économique, vol. 82, pp. 9-52. Title in English: Nonunitary models of household behavior: a survey.

[13] Davies, James B. and Junsen Zhang (1995), "Gender Bias, Investment in Children and Bequests", International Economic Review, Vol. 36, No. 3, August 1995.

[14] De la Croix David and Matthias Doepke (2003), "Inequality and Growth: Why Differential Fertility Matters", The American Economic Review, 93(4), 1091-1113.

[15] Doepke Matthias (2005), "Child Mortality and Fertility Decline: Does the BarroBecker Model Fit the Facts?", Journal of Population Economics 18(2), 337-366.

[16] Doepke Matthias and Michèle Tertilt (2007), "Women's Liberation: What's in It for Men?", mimeo.

[17] Dollar, David, and Roberta Gatti (1999), "Gender Inequality, Income, and Growth: Are Good Times Good for Women?", The World Bank - Policy Research Report on Gender and Development, Working Paper Series n1, May 1999.

[18] Echevarria Cristina and Antonio Merlo (1999), "Gender Differences in Education in a Dynamic Household Bargaining Model." International Economic Review, 40(2), pp. 265-286.

[19] Francois, Patrick (1998), "Gender discrimination without gender difference: theory and policy responses," Journal of Public Economics, 68(1), pp. 1-32.

[20] Francois, Patrick and Jan van Ours (2000), "Gender Wage Differentials in a Competitive Labour Market: The Household Interaction Effect," CEPR Discussion Papers n2603, November 2000.

[21] Friedberg, Leora, and Anthony Webb (2006), "Determinants and consequences of bargaining power in households", NBER Working Paper, No. 12367, National Bureau of Economic Research, July 2006.

[22] Hazan, Moshe and Hosny Zoabi (2006), "Does longevity cause growth? A theoretical critique", Journal of Economic Growth, 11:363-376.

[23] Iyigun Murat F. and Randall P. Walsh (2007), "Endogenous gender power, household labor supply and the demographic transition", Journal of Development Economics, January, 82(1): 138-155. 
[24] Klasen Stephan (1999), "Does Gender Inequality Reduce Growth and Development? Evidence from Cross-Country Regressions", The World Bank - Policy Research Report on Gender and Development, Working Paper Series n7.

[25] Knowles Stephen, Paula K. Lorgelly, and P. Dorian Owen (2002), "Are Educational Gender Gaps a Brake on Economic Development? some cross-country empirical evidence", Oxford Economic Papers, 54(1): 118-149.

[26] Lagerlöf Nils-Petter (2003), "Did Gender Equality Causes the Industrial Revolution?", Unpublished Working Paper.

[27] Lagerlöf Nils-Petter (2003), "Gender Equality and Long-Run Growth.", Journal of Economic Growth, 8, 403-426.

[28] Lührmann, Melanie, and Jürgen Maurer (2007), "Who wears the trousers? A semiparametric analysis of decision power in couples", Cemmap Working Paper, No. 25/07.

[29] Skaperdas S. ( 1996), "Contest success functions." Economic Theory , 283-90. 


\section{Recent titles}

\section{CORE Discussion Papers}

2008/6. Gabriella MURATORE. Equilibria in markets with non-convexities and a solution to the missing money phenomenon in energy markets.

2008/7. Andreas EHRENMANN and Yves SMEERS. Energy only, capacity market and security of supply. A stochastic equilibrium analysis.

2008/8. Géraldine STRACK and Yves POCHET. An integrated model for warehouse and inventory planning.

2008/9. Yves SMEERS. Gas models and three difficult objectives.

2008/10. Pierre DEHEZ and Daniela TELLONE. Data games. Sharing public goods with exclusion.

2008/11. Pierre PESTIEAU and Uri POSSEN. Prodigality and myopia. Two rationales for social security.

2008/12. Tim COELLI, Mathieu LEFEBVRE and Pierre PESTIEAU. Social protection performance in the European Union: comparison and convergence.

2008/13. Loran CHOLLETE, Andréas HEINEN and Alfonso VALDESOGO. Modeling international financial returns with a multivariate regime switching copula.

2008/14. Filomena GARCIA and Cecilia VERGARI. Compatibility choice in vertically differentiated technologies.

2008/15. Juan D. MORENO-TERNERO. Interdependent preferences in the design of equal-opportunity policies.

2008/16. Ana MAULEON, Vincent VANNETELBOSCH and Wouter VERGOTE. Von NeumannMorgenstern farsightedly stable sets in two-sided matching.

2008/17. Tanguy ISAAC. Information revelation in markets with pairwise meetings: complete information revelation in dynamic analysis.

2008/18. Juan D. MORENO-TERNERO and John E. ROEMER. Axiomatic resource allocation for heterogeneous agents.

2008/19. Carlo CAPUANO and Giuseppe DE FEO. Mixed duopoly, privatization and the shadow cost of public funds.

2008/20. Helmuth CREMER, Philippe DE DONDER, Dario MALDONADO and Pierre PESTIEAU. Forced saving, redistribution and nonlinear social security schemes.

2008/21. Philippe CHEVALIER and Jean-Christophe VAN DEN SCHRIECK. Approximating multiple class queueing models with loss models.

2008/22. Pierre PESTIEAU and Uri M. POSSEN. Interaction of defined benefit pension plans and social security.

2008/23. Marco MARINUCCI. Optimal ownership in joint ventures with contributions of asymmetric partners.

2008/24. Raouf BOUCEKKINE, Natali HRITONENKO and Yuri YATSENKO. Optimal firm behavior under environmental constraints.

2008/25. Ana MAULEON, Vincent VANNETELBOSCH and Cecilia VERGARI. Market integration in network industries.

2008/26. Leonidas C. KOUTSOUGERAS and Nicholas ZIROS. Decentralization of the core through Nash equilibrium.

2008/27. Jean J. GABSZEWICZ, Didier LAUSSEL and Ornella TAROLA. To acquire, or to compete? An entry dilemma.

2008/28. Jean-Sébastien TRANCREZ, Philippe CHEVALIER and Pierre SEMAL. Probability masses fitting in the analysis of manufacturing flow lines.

2008/29. Marie-Louise LEROUX. Endogenous differential mortality, non monitored effort and optimal non linear taxation.

2008/30. Santanu S. DEY and Laurence A. WOLSEY. Two row mixed integer cuts via lifting.

2008/31. Helmuth CREMER, Philippe DE DONDER, Dario MALDONADO and Pierre PESTIEAU. Taxing sin goods and subsidizing health care.

2008/32. Jean J. GABSZEWICZ, Didier LAUSSEL and Nathalie SONNAC. The TV news scheduling game when the newscaster's face matters. 


\section{Recent titles}

\section{CORE Discussion Papers - continued}

2008/33. Didier LAUSSEL and Joana RESENDE. Does the absence of competition in the market foster competition for the market? A dynamic approach to aftermarkets.

2008/34. Vincent D. BLONDEL and Yurii NESTEROV. Polynomial-time computation of the joint spectral radius for some sets of nonnegative matrices.

2008/35. David DE LA CROIX and Clara DELAVALLADE. Democracy, rule of law, corruption incentives and growth.

2008/36. Jean J. GABSZEWICZ and Joana RESENDE. Uncertain quality, product variety and price competition.

2008/37. Gregor ZOETTL. On investment decisions in liberalized electricity markets: the impact of price caps at the spot market.

2008/38. Helmuth CREMER, Philippe DE DONDER, Dario MALDONADO and Pierre PESTIEAU. Habit formation and labor supply.

2008/39. Marie-Louise LEROUX and Grégory PONTHIERE. Optimal tax policy and expected longevity: a mean and variance approach.

2008/40. Kristian BEHRENS and Pierre M. PICARD. Transportation, freight rates, and economic geography.

2008/41. Gregor ZOETTL. Investment decisions in liberalized electricity markets: A framework of peak load pricing with strategic firms.

2008/42. Raouf BOUCEKKINE, Rodolphe DESBORDES and Hélène LATZER. How do epidemics induce behavioral changes?

2008/43. David DE LA CROIX and Marie VANDER DONCKT. Would empowering women initiate the demographic transition in least-developed countries?

\section{Books}

Y. POCHET and L. WOLSEY (eds.) (2006), Production planning by mixed integer programming. New York, Springer-Verlag.

P. PESTIEAU (ed.) (2006), The welfare state in the European Union: economic and social perspectives. Oxford, Oxford University Press.

H. TULKENS (ed.) (2006), Public goods, environmental externalities and fiscal competition. New York, Springer-Verlag.

V. GINSBURGH and D. THROSBY (eds.) (2006), Handbook of the economics of art and culture. Amsterdam, Elsevier.

J. GABSZEWICZ (ed.) (2006), La différenciation des produits. Paris, La découverte.

L. BAUWENS, W. POHLMEIER and D. VEREDAS (eds.) (2008), High frequency financial econometrics: recent developments. Heidelberg, Physica-Verlag.

P. VAN HENTENRYCKE and L. WOLSEY (eds.) (2007), Integration of AI and OR techniques in constraint programming for combinatorial optimization problems. Berlin, Springer.

\section{CORE Lecture Series}

C. GOURIÉROUX and A. MONFORT (1995), Simulation Based Econometric Methods.

A. RUBINSTEIN (1996), Lectures on Modeling Bounded Rationality.

J. RENEGAR (1999), A Mathematical View of Interior-Point Methods in Convex Optimization.

B.D. BERNHEIM and M.D. WHINSTON (1999), Anticompetitive Exclusion and Foreclosure Through Vertical Agreements.

D. BIENSTOCK (2001), Potential function methods for approximately solving linear programming problems: theory and practice.

R. AMIR (2002), Supermodularity and complementarity in economics.

R. WEISMANTEL (2006), Lectures on mixed nonlinear programming. 